NBER WORKING PAPER SERIES

\title{
CLINICAL PATHWAYS TO DISABILITY
}

Mary Beth Landrum

Kate A. Stewart

David M. Cutler

Working Paper 13304

http://www.nber.org/papers/w13304

\section{NATIONAL BUREAU OF ECONOMIC RESEARCH 1050 Massachusetts Avenue \\ Cambridge, MA 02138}

August 2007

This work was funded by the National Institute of Aging (P30 AG12810 and R01AG019805) and the Mary Woodard Lasker Charitable Trust and Michael E. DeBakey Foundation. The views expressed herein are those of the author(s) and do not necessarily reflect the views of the National Bureau of Economic Research.

(C) 2007 by Mary Beth Landrum, Kate A. Stewart, and David M. Cutler. All rights reserved. Short sections of text, not to exceed two paragraphs, may be quoted without explicit permission provided that full credit, including $(\subset$ notice, is given to the source. 
Clinical Pathways to Disability

Mary Beth Landrum, Kate A. Stewart, and David M. Cutler

NBER Working Paper No. 13304

August 2007

JEL No. I10,I12

\section{ABSTRACT}

This paper examines the pathways by which individuals transition from healthy to disabled. Because of the high prevalence and costs associated with disability, understanding these pathways is critical to developing interventions to prevent or minimize disability. We compare two estimates of disabling conditions: those observed in medical claims and conditions indicated by the disabled individual. A small number of conditions explain about half of incident disability: arthritis, infectious disease, dementia, heart failure, diabetes, and stroke. These conditions show up in medical claims and self reports. A large number of elderly also attribute disability to old age and various symptoms. Because so many of the most disabling conditions do not have clear medical treatments, the outlook for major reductions in disability might be limited.

Mary Beth Landrum

Harvard Medical School

Department of Health Care Policy

180 Longwood Avenue

Boston, MA 02115-5899

landrum@hcp.med.harvard.edu

Kate A. Stewart

Department of Health Care Policy

180 Longwood Ave, Suite 301

Boston, MA 02115

kstewart@hsph.harvard.edu
David M. Cutler

Department of Economics

Harvard University

1875 Cambridge Street

Cambridge, MA 02138

and NBER

dcutler@harvard.edu 


\section{Introduction}

While disability declined over the course of the 1980's and 1990’s (Crimmins, Saito et al. 1997; Freedman and Martin 1998; Waidmann and Liu 2000; Cutler 2001; Manton and Gu 2001; Schoeni, Freedman et al. 2001; Freedman, Martin et al. 2002; Freedman, Crimmons et al. 2004; Spillman 2004), the prevalence of disability among the elderly remains high (Waidmann and Liu 2000; Schoeni, Freedman et al. 2001; Manton, Gu et al. 2006). Moreover, disability is associated with poor quality of life (Lamb 1996), high medical spending (Komisar, Hunt-McCool et al. 1997; Liu, Wall et al. 1997; Fried, Bradley et al. 2001; Guralnik, Alecxih et al. 2002; Chernew, Goldman et al. 2005) and increased mortality (Manton 1988; Guralnik, LaCroix et al. 1991; Ferrucci, Guralnik et al. 1996). Thus it is critical to understand the major clinical pathways through which the health of the elderly declines to be able to develop effective interventions to prevent or minimize disability in the elderly population.

In this paper, we analyze data from the National Long Term Care Survey (NLTCS), a longitudinal survey on a nationally representative sample of Medicare beneficiaries that has been linked to Medicare administrative data, to identify the major pathways through which the elderly become disabled. We compare two methods of identifying disabling conditions. First, using administrative billing data, we evaluate 31 potentially disabling clinical conditions and estimate the proportion of incident disability attributable to each condition. In order to better understand the association between medical conditions and disability we consider both simple binary measure of any disability in addition to measures that reflect severity (i.e. the total number of ADL and IADL disabilities) and types of limitations (i.e. mobility-related, cognitive or self-care). 
We also examine the relationship between medical conditions and the use of supportive and medical services. We hypothesize that different medical conditions lead to disability of varying severity and type and need for assistance. Identifying these differences may help to prioritize medical conditions for interventions to prevent or delay disability and to help design appropriate interventions for different types of disability.

In the second part of the paper, we compare these empirical results to respondents' self reported causes. We find that an important subset of newly disabled elderly did not report a chronic condition or an acute medical event when asked to identify the cause of their disability; rather, they cited symptoms or simply attributed their disability to old age. We explore whether respondents who attributed their disability to old age or symptoms differed from respondents who cited chronic or acute medical conditions in both patterns of disablement and health care utilization to better understand whether old age and symptom causes represent pathways to disability independent of diseases and conditions.

Our paper is structured as follows. First we discuss prior literature relevant to our analyses. We then describe our data and analytic methods and present our results. Finally we summarize our conclusions and discuss implications of our findings.

\section{Background:}

\section{Heterogeneity in the Disablement Process}


Disability in an elderly, non-working population is typically defined as the need for assistance ${ }^{1}$ with one or more or self care tasks, such as bathing or eating, called activities of daily living (ADLs), or tasks required to live independently, such as grocery shopping or preparing meals, called instrumental activities of daily living (IADLs). National surveys measuring disability in the elderly typically ask respondents about their ability to perform a set of ADL and IADL tasks, and often also ask respondents about physical limitations, such as difficulty walking long distances, going up stairs or grasping small objects.

Previous research has demonstrated that disability may develop as the result of a catastrophic event such as a stroke or a hip fracture, or as a progressive process associated with chronic and sometimes degenerative conditions such as arthritis or dementia (Ferrucci, Guralnik et al. 1996; Ferrucci, Guralnik et al. 1997; Wolff, Boult et al. 2005). Depending on the cause of disability, many elderly may recover from disability (Gill, Robison et al. 1997; Gill, Allore et al. 2006; Gill, Gahbauer et al. 2006) or they may progress to more severe states of disability. Among those who do not recover from disability, both theoretical and empirical work (Katz, Ford et al. 1963; Kempen and Suurmeijer 1990; Verbrugge and Jette 1994; Ferrucci, Guralnik et al. 1998) has suggested a hierarchy in physical limitations, and ADL and IADL tasks where an elderly person typically progresses from first having physical limitations to needing assistance with complex tasks (such as cooking, grocery shopping or managing money), progressing to needing assistance with some personal care needs such as getting out of bed and bathing, and then finally needing assistance with the most basic personal tasks such as toileting and feeding. However, there is disagreement across studies about the exact nature of the

\footnotetext{
${ }^{1}$ Some surveys ask respondents about the level of difficulty without assistance.
} 
disablement process (Siu, D.B. et al. 1990; Lazaridis, Rudberg et al. 1994; Dunlop, Hughes et al. 1997; Jagger, Arthur et al. 2001), which may be attributable to differing patterns of onset (i.e. catastrophic versus progressive) and likelihood of recovery.

Researchers have also demonstrated that disability, regardless of its cause, may be characterized as a continuum of difficulty and dependency (Fried, Herdman et al. 1991; Fried, Bandeen-Roche et al. 1996; Gill, Robinson et al. 1998; Fried, Bandeen-Roche et al. 2000; Fried, Young et al. 2001). For example, Gill et al. (1998) examined the relationship between difficulty and dependence in specific tasks and demonstrated that separate questions about the use of assistance and difficulty could be used to classify respondents into 3 ordered categories: independent without difficulty, independent with difficulty, and dependent. Similarly the work by Fried et al. $(2000,2001)$ identified a state of pre-clinical disability where respondents denied difficulty with a task, but nevertheless reported having modified their performance of the task because of health of physical problems. Respondents with pre-clinical disability were found to have intermediate levels of physical functioning between that of respondents who reported difficulty with tasks and those who reported neither difficulty nor modification, suggesting that modification without reported difficulty represents early manifestations of functional declines and a less severe form of disability.

Other empirical studies have conducted factor analyses to identify the number and types of underlying dimensions of disability (Fried, Ettinger et al. 1994; Spector and Fleishman 1998). For example, Spector and Fleishman (1998) found a great deal of correlation among 7 ADL and 9 IADL measures in approximately 3000 disabled respondents to the 1989 National Long Term Care Survey, so that a single factor that 
combined 15 of the 16 items adequately described the observed patterns. Fried et al (1994) examined 17 physical limitations, ADL and IADL items in 5,201 communitybased elderly adults living in one of four US communities; they found that self-reported difficulty with these 17 items could be partitioned into 4 factors representing mobility problems, difficulty with complex tasks, difficulty with self-care and upper extremity limitations. These four factors explained $48 \%$ of the total variance in the 17 items. Researchers have also used Grade of Membership models, an extension of latent class models that hypothesize different underlying types of respondents with different patterns of disability, to examine profiles of disability (Lamb 1996; Manton, Stallard et al. 1998). Prior research has also documented specificity in the associations between conditions and specific types of limitations. Arthritis has generally been found to be strongly associated with functional limitations and moderate ADL limitations (Verbrugge, Lepkowski et al. 1991; Fried, Ettinger et al. 1994; Guccione, Felson et al. 1994; Manton, Stallard et al. 1998) while stroke and dementia have been consistently linked with both IADL limitations and more severe disability in self-care tasks (Fried, Ettinger et al. 1994; Guccione, Felson et al. 1994; Manton, Stallard et al. 1998). Similar patterns are found in respondents self-reports of the causes of their limitations (Ford, Folmar et al. 1988; Ettinger, Fried et al. 1994; Valderrama-Gama, Damian et al. 2002). Arthritis was most often cited as the cause of limitations in mobility related tasks, including getting out of bed and getting around inside; heart and lung diseases were the most often cited causes for aerobic tasks, such as walking half a mile, while stroke and dementia were most often associated with cognitive and self care tasks. 
In this paper, we evaluate the association of specific diseases and conditions with varying types and severity of disability to better understand the association between medical conditions and the disablement process. We also use the total number of limitations as a proxy for severity of disability, and evaluate whether severity varies across conditions. We further examine reported medical care and assistive services used by disabled respondents, hypothesizing that greater use of medical care and assistive services may reflect more severe disability.

\section{Chronic Conditions Leading to Disability}

A large body of research has demonstrated the importance of chronic disease as the primary contributor to disability (Kosorok, Omenn et al. 1992; Guccione, Felson et al. 1994; Boult, Altmann et al. 1996; Ferrucci, Guralnik et al. 1997; Aguero-Torres, Fratiglioni et al. 1998; Dunlop, Manheim et al. 2002; Wolff, Boult et al. 2005; Song J, Chang RW et al. 2006). However, these studies often limit attention to the noninstitutionalized elderly population, thus omitting important conditions such as dementia, or focus on a small number of conditions. Further, studies were often conducted on nonrepresentative samples. In this paper, we extend these prior results by examining the share of disability attributable to a wide range of clinical conditions in a nationally representative sample.

\section{Characteristics of Disabled Respondents Attributing Disability to Symptoms or Old age}

The prior literature provides conflicting evidence on whether chronic disease is responsible for the majority of disability attributed to "old age” or symptoms by elderly respondents, or whether these respondents are identifying a pathway to disability that is largely independent of chronic disease. Research supporting the idea that the elderly may 
attribute declines in health related to chronic conditions to old age or symptoms include a study of 230 community dwelling elderly that found that those who attributed their disability to old age were similar to those not reporting old age as the cause of their disability in terms of age, gender and race, but were more likely to have chronic conditions, such as arthritis, heart disease or hearing difficulties (Williamson and Fried 1996). In addition, several regional studies (Ettinger, Fried et al. 1994; Williamson and Fried 1996; Leveille, Fried et al. 2002; Leveille, Fried et al. 2004) demonstrated strong relationships between specific diseases and symptoms. For example, elderly who cited pain as a primary cause of their disability were also likely to cite arthritis when asked for a condition cause, and they had a high prevalence of arthritis confirmed by clinical examination; disability attributed to fatigue and shortness of breath was associated with lung and heart disease.

In contrast, Leveille et al. (2002) found that women who were unable to cite specific chronic conditions causing their disability were often better able to name symptom causes. They also found little association between certain symptoms, such as fear of falling and general weakness, and chronic conditions, suggesting that at least some of the disability attributed to symptoms or old age is not directly related to common disabling chronic conditions. The literature on frailty generally supports the notion of a pathway to disability that is not a direct result of chronic disease, but instead is associated with age-related loss of physical condition and reserve. For example, Guralnik et al. (1995) found that objective measures of physical functioning among non-disabled elderly predicted subsequent disability even after controlling for chronic conditions (Guralnik, Ferrucci et al. 1995). Other authors have argued for the importance of frailty as a 
separate concept from comorbidity and have found that frailty is associated with disability independently of chronic disease (Ferrucci, Guralnik et al. 1996; Lunney, Lynn et al. 2003; Fried, Ferrucci et al. 2004).

In this paper, we seek to resolve some of this conflict by further analyzing the characteristics of respondents who attribute disability to either old age or symptom causes as opposed to chronic or acute medical conditions. In particular, we compare severity of disability and use of medical and assistive services to identify systematic differences across these populations that may suggest a pathway to disability independent of diseases and conditions.

\section{Data and Methods}

We used data from the National Long Term Care Survey. The NLTCS is a longitudinal, nationally representative survey of the Medicare population that was designed to study changes in the health and functional status of elderly Americans. Starting in 1982, a random sample of approximately 20,000 Medicare beneficiaries completed a screening interview. Those found to have a chronic disability ${ }^{2}$ were then asked to complete a detailed survey. Follow-up surveys were conducted in 1984, 1989, 1994 and 1999. Chronically disabled respondents who survived until the next survey

\footnotetext{
${ }^{2}$ Defined as residence in a long term care facility, the inability to perform one of 9 ADLs (eating, getting in or out of bed, getting in or out of chairs, walking around inside, going outside, dressing, bathing, getting to the bathroom or using the toilet, controlling bowel movements or urination) without personal assistance or special equipment or one of 7 IADLs (preparing meals, laundry, light housework, shop for groceries, manage money, take medicines, use the telephone) without help because of disability or health problem for at least 90 days.
} 
were automatically contacted for detailed follow-up surveys. In addition, at each subsequent wave of the survey, a sub-sample of non-disabled respondents from the previous wave were contacted for a new screener interview and those found to be chronically disabled were asked to complete the detailed survey. Finally, at each wave a random sample of approximately 5,000 Medicare beneficiaries who reached age 65 between waves of the survey were screened in order to maintain a nationally representative sample of the Medicare population. Over the 5 waves of the survey more than 90,000 screening interviews were performed, leading to over 32,000 detailed interviews (Manton and Gu 2001). Approximately 20\% of 1994 and 1999 surveys were completed by proxy respondents (Freedman, Crimmons et al. 2004).

The NLTCS has several important strengths. First, the longitudinal design with age-in cohorts allows us to obtain national estimates. Second, response rates for both screener interviews and detailed surveys were over 95\% in each wave. In addition, survey data has been linked to Medicare administrative data, providing detailed information on the existence of clinical conditions for which respondents were receiving care.

Study Cohorts:

Our analyses are based on non-disabled respondents from the 1994 survey whose disability and vital status is known in 1999. From the cohort of 12,366 participants in the 1994 survey who were not chronically disabled, we excluded a) 1,568 participants who were not 65 years old on January 1, 1992, in order to assure complete claims data in the baseline period prior to 1994, b) 10 participants who could not be matched to Medicare data, c) 1,231 respondents whose disability status was unknown in 1999 because they 
were not re-sampled ( $n=752)$ or lost to follow-up ( $n=479)$, and d) 1,830 participants enrolled in an HMO for 6 months or longer, leaving an analytic cohort of 7,727 participants.

\section{Disability Measures:}

Subjects were considered newly disabled if they reported any ADL or IADL limitations in the 1999 detailed survey $^{3}$ or if they were institutionalized at the time of the 1999 survey. Limitations on 6 specific ADL tasks (eating, getting in and out of bed, getting around inside, dressing, bathing, toileting) were obtained from the detailed interviews of both community based and institutionalized respondents. Limitations on 8 specific IADL tasks (light housework, laundry, preparing meals, shopping for groceries, getting around outside, managing money, taking medications, using the telephone) and 9 functional limitations (difficulty climbing a flight of stairs, walking across a room, bending to put on socks, lifting a 10-lb object, reaching above the head, using fingers to grasp and handle small objects, seeing well enough to read newsprint, speaking, and hearing) were also obtained from the detailed interviews with community-based respondents.

We grouped the 14 individual ADL and IADL tasks into categories for several analyses. To explore the empirical relationships among the specific tasks, we fit a principal component model to the 5,787 non-disabled respondents in the 1994 NLTCS who survived to 1999 and completed a screener interview. We found that 3 factors could

\footnotetext{
${ }^{3}$ Respondents were classified as disabled on an ADL task if they reported that someone helped them perform the task, if someone stayed nearby in case they needed help, or if they used special equipment to perform the task. Respondents were classified as disabled on an IADL task if they report that they cannot do the task because of disability or health problem.
} 
explain $85 \%$ of the total variance in the 14 items. Similar to Fried et al. (1994), one of these factors was strongly associated with more complex IADL tasks requiring cognitive abilities (cooking, laundry, light housekeeping, grocery shopping, managing money and using the telephone). Also as in the Fried et al. analysis, difficulty getting around outside (typically considered an IADL) was more strongly related to mobility-related ADL tasks than the other IADL tasks. Thus, we used the aggregation of tasks employed by Fried et al (1994) to summarize our 14 ADL and IADL measures into three major types of disability: 1) mobility disability (getting out of bed, walking inside, walking outside the home), 2) disability in complex tasks (cooking, laundry, light housework, grocery shopping, managing money and using the telephone) and 3) disability in self-care tasks (eating, dressing, toileting and bathing). Following theoretical and empirical work suggesting hierarchies in the disablement process, we consider disability in basic selfcare tasks to represent the most severe type of disability and mobility disability to represent early manifestations of loss of functional abilities.

Detailed interviews of the community-based disabled also asked respondents to report the heath conditions they believed were the cause of their disability. Respondents were able to list up to 10 conditions, and eighty-nine percent of the community-based respondents (n-892) provided at least one response. We developed a coding scheme that summarized free text responses into: a) chronic conditions b) acute events c) physical symptoms that were not directly linked to clinical condition (such as weakness, lack of balance, or pain) or d) old age. These categories were not mutually exclusive, as respondents often reported multiple causes. We also coded a set of binary indicators of specific chronic conditions and acute events, and modified a recently validated taxonomy 
of self-reported symptom causes to classify symptom causes as pain, balance, weakness, endurance or other symptom.(Leveille, Fried et al. 2004) Both authors independently coded the free-text responses. Agreement was high, with kappas ranging from 0.7 to 1.0 for chronic and acute conditions. Agreement was slightly lower for symptom causes (ranging from 0.3 for upper extremity pain to 1.0 for hearing). Final coding was based on consensus when there was disagreement.

\section{Other Variables:}

Mortality and information about the existence of 31 chronic conditions ${ }^{4}$ were obtained from Medicare administrative data. We examined the prevalence of chronic conditions over two time frames. Participants were coded as having the clinical condition at baseline if there was at least one inpatient claim or 2 non-hospital claims (outpatient, home health, SNF or hospice) with a primary or secondary diagnosis of interest between January 1, 1992 and December 31, 1994 ${ }^{5}$. Similarly, participants were coded as

\footnotetext{
${ }^{4}$ These mutually exclusive categories were previously defined on the basis of prevalence of ICD-9 diagnosis and their observed relationship with disability (McClellan, M. and L. Yan (2000). Understanding disability trends in the U.S. elderly population: The role of disease management and disease prevention. Department of Economics. Stanford University, Cutler, D. M. (2005). Intensive medical technology and the reduction in disability. Analyses in the Economics of Aging. D. A. Wise. Chicago, The University of Chicago Press: 161-184. See Table A1 in the Appendix for list of clinical conditions and associated ICD-9 codes.

${ }^{5}$ We examined several alternative coding schemes for clinical conditions. First we considered rules that considered a respondent to have the condition if there were any claims for the condition (inpatient, outpatient, SNF, home health or hospice). In addition, we examined a two-year window (Jan 1 1993-Dec 31 1994) for conditions existing prior to baseline. Based on examination of the prevalence of conditions, the persistence of conditions across time frames and the association with self-reported conditions, in
} 
developing the condition between surveys if they had at least one inpatient claim or 2 non-hospital claims with a primary or secondary diagnosis of interest between January 1, 1995 and December 31, 1999. We then combined these two timeframes and examined the impact of having the condition either at baseline or developing the condition between the surveys on the likelihood of developing disability ${ }^{6}$.

Demographic variables (age, gender, race and marital status) were obtained from the screener surveys. Detailed interviews with community-based disabled respondents provided information on the use of health care and assistive services, including any nursing home stays, hospitalizations in the past year, visits in the past month to the emergency room, physicians, and physical, occupational, speech or hearing therapists, as well as home health services in the past month, and the number of prescription medications obtained in the previous month. The detailed survey also asked respondents about their living arrangements, including whether they were living in an assistive living setting with board and/or personal care services available.

Analyses:

addition to an examination of prior literature, we determined that a 3 year look-back for the baseline period and the requirement of at least 2 non-inpatient diagnoses provided the best compromise between sensitivity and specificity for a majority of the conditions.

${ }^{6}$ We included conditions developed between the surveys in order to study conditions such as dementia that may be disabling over a short time frame. The associations between conditions and disability should be interpreted cautiously as we do not know when the participant became disabled and thus some of the new conditions may follow or even be a result of declining functional status (for example, a fracture may be the result of weakness and/or loss of balance). However, for a majority of these conditions, the more likely scenario is that the condition led to functional limitations and resulting disability. 


\section{Empirical Pathways to Disability}

We fit multinomial regression models to estimate the relative importance of the 31 clinical factors in explaining any disability and differing types of disability. We fit four separate models for any disability, mobility disability, disability in complex tasks and disability in self-care tasks. In each case, the dependent variable was a categorical variable with three levels: disabled in at least one specific task in the group, alive and not disabled in at least one task in the group, or died before the 1999 survey. All regression models included age (in 5 year categories), gender, marital status in 1994, race (coded as white, black or other), the set of 31 indicators variables for each of the clinical conditions and a binary variable equal to 1 if the respondent did not have any medical claims during the study period. In addition, we examined interaction terms to understand the extent to which combinations of diseases have synergistic effects on disability. To focus the exploration of interactive effects, we included all pair-wise interactions of conditions that were each estimated to cause at least 5\% of incident of any type disability as measured by the adjusted attributable fraction.

We used results from the multinomial regression models to compute adjusted attributable fractions (Greenland and Drescher 1993). Attributable fractions estimate the importance of the condition from a population perspective by combining the prevalence of the factor with the strength of the association between the factor and future disability status. Specifically, for each condition we estimated the reduction in each type of disability that could be achieved by preventing the condition as the average predicted probability of becoming disabled if none of the participants had the condition, holding all other covariates at their observed values. A few clinical conditions were found to be 
protective for mortality, disability, or both. As these effects are likely markers for either improved access to treatments or relative health that allows for treatment of milder chronic conditions (Jencks, Williams et al. 1988; Iezzoni, Foley et al. 1992), we did not estimate attributable fractions for conditions that were protective of both disability and death. In cases where a condition was estimated to be protective for death but positively associated with disability, we computed attributable fractions for disability by setting all negative mortality coefficients equal to zero and rescaling the intercept terms to match observed overall proportions in our data.

\section{Characteristics of pathways}

We examined how the empirical pathways differed in terms number of limitations and use of medical and assistive services to understand whether various pathways are associated with more intensive medical and social service needs. We focused on the conditions that were each responsible for at least $5 \%$ of incident disability. Note these groups are not mutually exclusive, and in fact, there is a great deal of co-occurrence of disabling diseases in this population. In these descriptive analyses, for each of the major pathways, we compared disabled respondents with the condition to those without evidence of the condition in their medical claims.

\section{Self-reported causes of disability}

Our second set of analyses describes self-reported causes of disability in the newly disabled community-dwelling cohort (institutionalized respondents were not asked to report the cause of their disability). We also examined the distribution of the number of functional limitations and limitations in IADL and ADL tasks and described reported use of medical and assistive services. In all analyses, we compared newly disabled 
community dwelling respondents reporting old age or symptom causes to those who reported only medical conditions as the cause of their disability.

Analytic weights that account for complex sampling scheme were used in all analyses to provide estimates that reflect the national population of non-disabled Medicare beneficiaries aged 67 and older in 1994. Specifically, cross-sectional weights that accounted for complex sampling scheme and non-response to the 1994 survey were augmented to account for sub-sampling of healthy respondents for a screener interview in 1999, non-response to the 1999 screener interview, and exclusion of patients enrolled in an HMO by redistributing weights for healthy respondents in 1994 who were excluded from our analyses to the respondents in our sample within cells defined by age and sex. Statistical tests and standard errors were also corrected for the complex survey design using approximations based on Taylor-series linearizations.

\section{Results}

\section{Empirical Pathways to Disability}

Sixty-six percent of non-disabled respondents in 1994 survived and remained non-disabled to 1999 , while $15.1 \%$ became disabled over the 5 year period and $18.9 \%$ died between survey waves. Twelve, ten, and eleven percent of non-disabled respondents to the 1994 survey developed one or more mobility-related, complex task or self-care disabilities respectively between survey waves. Death and incident cases of disability were more common among older, African American, and unmarried respondents (Table 1). Females were more likely to become disabled but less likely to have died compared to males. Hip and pelvic fractures, dementia, Parkinson’s and 
related diseases, depression, and stroke had the strongest association with new cases of disability. Most disabling conditions were also associated with death.

Regression models with main effects for the 31 conditions identified six clinical conditions - arthritis, infectious disease, dementia, heart failure, diabetes and stroke that contributed to at least $5 \%$ of new cases of disability. Only $17 \%$ of elderly respondents did not have one of these six conditions and a majority (54\%) had two or more.

Our final regression models included 15 pairwise interactions between the 6 largest contributors to overall disability. Regression results are presented in Table 2. Several interactions were found to be important in these analyses. For any disability, the interaction between diabetes and arthritis was positive, suggesting that these two conditions have synergistic effects such that having both conditions was more disabling than would be expected by the effects of each individual condition. In contrast, two interactions with dementia were negative (stroke*dementia and heart failure*dementia), suggesting that in the presence of a highly disabling condition like dementia, other conditions have effects that are dampened relative to what would be expected when the disease occurs in isolation. These general patterns were found in the analysis of each type of disability, although the strength of the interactions (and their statistical significance) varied some across the three types. In addition, several new interactions were important for disability in complex tasks. In particular, stroke exacerbated the effects of both diabetes and heart failure in disability in complex tasks.

Dementia in the absence of heart failure, stroke, arthritis, infectious disease or diabetes had the strongest association with new disability of all types in multinomial 
regression models (OR for any disability relative to remaining alive and health=8.0; 95\% $\mathrm{CI}=[4.6,13.8])$. Other conditions with strong relationships with incident disability included Parkinson's and related disorders (OR for any disability =2.3 [1.8,3.0]), hip and pelvic fractures (OR for any disability =2.1 [1.6,2.9]), colorectal and lung cancer (OR for any disability $=1.9[1.4,2.4])$, acute renal failure (OR for any disability $=1.7[1.1,2.7])$ and heart failure in the absence of stroke, arthritis, infectious disease, diabetes or dementia (OR for any disability =1.6 [1.1,2.4]). While many conditions were strongly related to all three types of disability, the strength of the association varied for many of these conditions. For example, infectious disease, heart failure and arthritis had the strongest relationship with complex task disability, while hip and pelvic fractions were strongly associated with mobility and self-care disability.

In adjusted models, divorced, separated or never married respondents and females were more likely to become disabled. Race was not significantly associated with future status after controlling for the other factors. We found some differences in the effect of demographic characteristics on disability. In particular, women were more likely than men to report new disabilities in mobility and self-care tasks but not with complex tasks.

Age, even after adjusting for a set of 31 clinical conditions and interactions among the top six contributors, was strongly associated with disability. For example, the adjusted odds of becoming disabled relative to remaining alive and non-disabled was 3.7 (95\% CI=[2.7,5.1]) times higher for 80-84 year olds compared to 67-70 year olds. This represents a $23 \%$ decline in the effect of age relative to a model that controlled only for demographic factors.

\section{Largest Contributors to Disability}


Figures 1-4 display adjusted attributable fractions for each type of disability based on regression results. Attributable fractions, a combination of the prevalence of the conditions and their association with disability, estimate the proportion of disability that was explained by each condition, holding all other characteristics of the respondents constant. Although arthritis was only moderately associated with incident disability (OR for any new disability=1.5 [1.1,2.1]), because it is common condition it was the largest contributor, accounting for $13 \%$ of any new disability. Five other conditions -infectious diseases, dementia, heart failure and arrhythmia, diabetes and stroke contributed to at least 5 percent of new cases of disability and these six top conditions together explained almost half (48\%) of new cases.

We observed some heterogeneity in these pathways across the different types of disability (Figures 2-4). Arthritis was the largest contributor to impairments in mobility (explaining $17 \%$ of this type of disability), but played a much less prominent role in disability in complex tasks. Similarly, stroke contributed most to less severe forms of disability and explained only $4 \%$ of disability associated with self-care tasks. Dementia was a large contributor to overall disability, was responsible for almost a quarter of disability in completing complex tasks and was also the largest contributor to the most severe form of disability, dependence in self-care tasks. Ischemic heart disease, which was not found to be a prominent contributor to overall disability, explained more than one in 20 cases of new disability in self-care tasks. Not all diseases, however, demonstrated such specificity. For example, heart failure and infectious disease played a prominent role in all three types of disability, each explaining between 10 and $15 \%$ of each type of disability. 


\section{Characteristics of pathways}

Almost all (96\%) of newly disabled respondents had at least one of the top six conditions leading to disability - dementia, stroke, heart failure, infectious diseases, arthritis, or diabetes. Moreover there was substantial overlap among the six pathways: only $12 \%$ of the newly disabled cohort had only one of the six conditions and two thirds had three or more.

Figure 5 displays the average number of functional limitation, IADL limitations, and ADL limitations in newly disabled respondents according to diagnoses in their medical claims (Table A2 in the appendix provides information on specific limitations). The newly disabled cohort had a large number of each type of limitation. Physical limitations in particular were quite prevalent with community-dwelling respondents reporting 3.3 limitations on average. Even the most severe forms of disability, inability to perform ADL tasks, were prevalent, with respondents reporting on average 2.6 ADL limitations. Newly disabled respondents with dementia reported the largest number of limitations of each type, including more than 4 IADLs on average. Newly disabled respondents with each of the top six conditions were more likely to report functional limitations compared to those not reporting the condition and most of the conditions (dementia, stroke, heart failure and infectious diseases) were associated with higher number of limitations of each type. However, neither arthritis nor diabetes was associated with higher numbers of IADL limitations and diabetes was not associated with a higher number of ADL limitations.

We present self-reported utilization of health care and assistive services in Table

3. Approximately $20 \%$ of the newly disabled cohort was institutionalized, of those living 
in the community $12 \%$ reported past nursing home stays; however, only a small number reported living in assistive living facilities Institutionalization and nursing home stays were most likely among newly disabled respondents with dementia, stroke, heart failure or infectious diseases. Those with dementia were also most likely to receive supportive services, including physical and occupational therapy and home health services. In

addition, health care use was high among this cohort. Approximately half of newly disabled respondents reported a physician visit in the prior month, over a third reported a hospitalization in the prior year, and they reported filling an average of 4 prescriptions in the past month. Health care utilization was highest among respondents with stroke, heart failure and diabetes, and lowest among respondents with dementia and arthritis.

\section{Self-reported causes of disability}

Over half of the newly disabled community-dwelling respondents reported a chronic condition was a factor in their limitations, while 30\% reported an acute event (Table 4). Musculoskeletal problems and cardiovascular diseases were the most common reported cause of disability. Dementia, lung diseases, diabetes, eye diseases, surgeries, fractures and falls were also commonly cited causes of disability. While a majority of respondents reported chronic or acute medical conditions as the cause of their disability, $30 \%$ reported symptoms that were not directly linked to a chronic or acute health problem, and $14 \%$ of respondents reported that old age contributed to their disability. Respondents often cited multiple causes and those citing symptoms and old age often cited specific acute and chronic conditions as well. We report conditions cited by these respondents in Table 5. Among respondents reporting symptoms, 44\% and 21\% reported at least 1 chronic or acute condition, respectively, while the remaining 41\% 
reported only symptoms. Heart disease was the most frequently reported condition among those citing symptom causes. Only $8 \%$ of those reporting symptom causes also cited old age as a contributor. Old age was the only reported cause for forty-six percent of respondents attributing their disability to old age. About a third of respondents citing old age as a cause of their disability also cited a chronic condition and 13\% cited acute causes. Arthritis was the most commonly cited condition among those attributing disability to old age.

Table 6 reports characteristics of newly disabled respondents according to selfreported cause of disability. Respondents citing old age were more likely to be female, African American and widowed at the time of the 1999 survey and were approximately 4 years older (80.2 versus 75.8 years old) than those citing only medical causes. However, they were no more likely to have any of most disabling clinical conditions, and in fact were less likely to have diagnoses of arthritis, diabetes, Parkinson's and related diseases and respiratory diseases compared to respondents who did not cite old age as a cause of their disability. Respondents reporting symptoms were also often less likely to have disabling conditions compared to those reporting chronic condition or acute event. However, patients reporting pain/discomfort or weakness as a cause of their disability were more likely to have evidence of arthritis. Respondents citing weakness were more likely to be female. However, the sample sizes were small in several of these categories making precise inference difficult.

Types and Severity of Limitations

We report the number of functional limitations, IADL limitations and ADL limitations according to self-reported cause of disability in Figure 6 (Table A3 in the 
appendix provides information on specific limitations). Newly disabled respondents reporting only chronic or acute conditions reported more functional limitations than respondents who reported old age, and significantly more ADLs and IADLs then respondents who reported symptoms.

\section{Medical and Assistive Services}

We present self-reported utilization of health care and assistive services in Table 7. Past nursing home stays were highest among those who reported clinical causes and lowest among those citing symptoms. Respondents citing symptom causes were also less likely to report use of physical or occupational therapy services. Consistent with the observation that respondents citing old age or symptoms were less likely to have evidence of clinical conditions in their medical claims, these respondents have lower levels of health care utilization (physician visits, medications, and hospitalizations). However, health care use was high in all groups. Forty percent of respondents citing old age reporting a physician visit in the past month and a quarter reported being hospitalized in the previous year, suggesting sufficient contact with the health care system to receive care for chronic conditions.

\section{Discussion}

Analyzing 31 clinical conditions, we estimated that arthritis, dementia, infectious diseases, heart failure, diabetes and stroke each explained at least 5\% of incident disability. These top 6 conditions together explained almost half of new disability (48\%). Consistent with these findings, arthritis, stroke, dementia and heart disease were the conditions most often mentioned among respondents who reported an acute or chronic condition as a cause of their limitation. 
We also found that newly disabled respondents with these six conditions typically experience problems in multiple categories of functional limitations, ADL and IADL tasks. Elderly patients with any of these six conditions were also more likely to have been hospitalized in the past year and had a greater average number of prescription drugs in the past month compared to the average newly disabled patient. However, there were differences across these pathways in the types of disability experienced and in the use of services. For example, dementia represents the pathway most strongly associated with the most severe types of disability and the largest number of reported limitations. Newly disabled respondents with dementia were also the heaviest users of supportive services, including nursing home residence. In contrast, arthritis, while being the largest contributor to overall disability, was associated most strongly with mobility limitations and newly disabled respondents with arthritis used relatively few supportive and medical services.

Our comparison of newly disabled respondents who attributed their disability to old age or symptoms to those citing chronic or acute medical conditions also demonstrated important differences. First, we found that those who reported age as a cause of their disability had similar or lower levels of disabling conditions compared to those who reported a clinical condition. In addition, newly disabled respondents attributing disability to symptom causes or old age tended to have less severe disability and use fewer supportive services. While those citing old-age had lower use of health care, there were sufficient interactions with clinicians (42\% report visit with a physician in prior month) to have had chronic disease diagnosed. These results suggest those reporting old age or symptoms represent a different “pathway”, i.e. frailty or “pre- 
clinical” disease that leads to their disability. The importance of infectious diseases in our empirical models also suggests a role for heightened vulnerability in the elderly as past diagnoses of infectious diseases may be a marker for frailty.

We found that self-reported causes and empirical analyses of claims-based measures provided complimentary information. Claims-based diagnoses were available on all respondents and empirical models allowed us to estimate the fraction of disability attributable to each condition independently of the other conditions. However, binary measures of diagnoses from medical claims may not adequately capture disease severity. In addition, claims-based analyses did not capture most visual and hearing impairments, which have been shown to be important correlates of disability here and in other studies (Kosorok, Omenn et al. 1992; Dunlop, Manheim et al. 2002). Analyses based on selfreported causes, which were only collected from community-based respondents, may underestimate the effect of highly disabling conditions like dementia. Given the differing strengths and weaknesses of clinical data and self-reports, future attempts to measure causes of disability should combine the two approaches.

These analyses have important implications. First, an understanding of the major contributors to disability in the late 1990's, provides insight into potential future trends in the health of the elderly. We found that conditions without effective medical treatments - in particular dementia - were major contributors to disability in older persons.

Alzheimer's and other forms of dementia are highly disabling progressive diseases with few effective interventions to slow their progression,(Cummings and Cole 2002) Until effective treatments are found, dementia-related disability is likely to increase in importance. In contrast, many conditions, in particular stroke, heart disease and arthritis, 
are amenable to both medical and lifestyle interventions, suggesting that increased use of effective medical therapies and control of risk factors could lead to continued improvement in the health of the elderly.(Manton 1989; Boult, Altmann et al. 1996; Singer and Manton 1998) However, obesity rates continue to rise and obesity is a risk factor for four of the six most important pathways in our analysis (arthritis, heart failure, stroke and diabetes). The increase in obesity rates in the elderly and non-elderly population, coupled with increases in disability rates in younger populations, have led others to suggest that disability rates in older persons will increase in the future.(Lakdawalla, Bhattacharya et al. 2004; Leveille, Wee et al. 2005) Moreover, a recent study found that obesity contributed to an increasing number of cases of arthritis between 1971 and 2002.(Leveille, Wee et al. 2005)

Second, our results suggest potential avenues for medical and other interventions to alleviate dependence in the elderly. We found that various diseases and conditions are specific to different types of disability. This suggests that interventions to prevent or reduce disability may be targeted to different types of tasks, depending on the medical condition experienced by the patient. Interventions likely need to be targeted to multiple ADL and IADL tasks within a category of disability, as the six diseases and conditions were associated with limitations in multiple tasks.

In addition, medical care and assistive service utilization varied across conditions, suggesting that there may be variation in opportunities to intervene through medical and non-medical services. For example, while respondents with dementia had relatively low rates of hospitalizations and physician visits, almost half were institutionalized and $20 \%$ were using home health services. Until effective medical interventions are available for 
dementia patients, current interventions may be best targeted through supportive care services and within their living environment. In contrast, newly disabled respondents with arthritis were relatively infrequent users of intensive inpatient or nursing home care, but had higher than average use of medications and physician visits, suggesting that interventions for disability assessment and prevention services among these patients may be most effectively conducted by physicians. For all diseases and conditions studied, improved medical care in the future may help to reduce disability.

Our analyses of newly disabled respondents attributing their disability to old age or symptoms suggest a greater focus on physician-based assessment of preclinical disease and treatment of symptoms in order to prevent disability. The large number of disabled respondents in the community who cited old age as a cause of disability may also imply that elderly respondents have low expectations for interventions, either medical or otherwise, to help them function independently. Physician-based interventions may help to educate patients about expectations for functioning and additional medical care treatments and interventions to minimize disability.

In conclusion, we identified 6 major clinical pathways to disability that account for almost half incident disability, but differ in the types of disability experienced and use of medical and assistive services. These results have important implications for future trends in the health of the elderly population, highlighting substantial challenges to continued improvement in disability. 
Table 1. Health status at follow-up according to demographic and clinical characteristics of study cohort

\begin{tabular}{|c|c|c|c|c|c|}
\hline & \multirow{2}{*}{$\begin{array}{c}\text { \% of } \\
\text { Cohort } \\
(\mathrm{N}=7727)\end{array}$} & \multicolumn{4}{|c|}{ Status at 1999 Interview (\%) } \\
\hline & & $\begin{array}{c}\text { Newly } \\
\text { Disabled }\end{array}$ & Deceased & $\begin{array}{c}\text { Alive and } \\
\text { Non- } \\
\text { Disabled }\end{array}$ & $P$ value \\
\hline All respondents & 100 & 15.1 & 18.9 & 65.9 & \\
\hline Age in 1994 & & & & & $<0.001$ \\
\hline $67-69$ & 22.5 & 8.8 & 11.1 & 80.2 & \\
\hline $70-74$ & 34.3 & 10.5 & 13.9 & 75.6 & \\
\hline 75-79 & 23.6 & 18.6 & 20.9 & 60.5 & \\
\hline 80-84 & 13.0 & 25.6 & 28.5 & 45.9 & \\
\hline $85-89$ & 5.3 & 29.4 & 43.4 & 27.2 & \\
\hline 90 and over & 1.3 & 21.5 & 57.5 & 21.0 & \\
\hline Race & & & & & 0.008 \\
\hline White & 91.7 & 15.1 & 18.7 & 66.2 & \\
\hline Black & 6.6 & 16.3 & 24.1 & 59.7 & \\
\hline Other & 1.7 & 9.6 & 12.3 & 78.2 & \\
\hline Gender & & & & & $<0.001$ \\
\hline Female & 56.7 & 17.7 & 15.6 & 66.7 & \\
\hline Male & 43.3 & 11.7 & 23.3 & 65.0 & \\
\hline Marital Status in 1994 & & & & & $<0.001$ \\
\hline Married & 56.5 & 12.4 & 16.3 & 71.3 & \\
\hline Widowed & 32.0 & 19.4 & 21.6 & 59.0 & \\
\hline $\begin{array}{l}\text { Divorced/separated/ } \\
\text { never married }\end{array}$ & 9.0 & 18.2 & 21.2 & 60.5 & \\
\hline Unknown & 2.5 & 11.5 & 36.2 & 52.3 & \\
\hline \multicolumn{6}{|l|}{ Clinical Conditions $^{\dagger}$} \\
\hline Hip \& pelvic fracture & 6.1 & 34.6 & 28.8 & 36.6 & $<0.001$ \\
\hline $\begin{array}{l}\text { Dementia \& organic } \\
\text { brain diseases }\end{array}$ & 15.3 & 33.9 & 36.5 & 29.6 & $<0.001$ \\
\hline $\begin{array}{l}\text { Paralysis, Parkinson's } \\
\text { and related diseases }\end{array}$ & 10.7 & 30.3 & 34.8 & 34.9 & $<0.001$ \\
\hline Depression & 13.3 & 27.1 & 22.7 & 50.3 & $<0.001$ \\
\hline Stroke & 29.9 & 23.5 & 25.7 & 50.9 & $<0.001$ \\
\hline Other mental disorders & 24.2 & 22.3 & 24.6 & 53.1 & $<0.001$ \\
\hline Chronic renal failure & 6.9 & 22.1 & 44.3 & 33.6 & $<0.001$ \\
\hline $\begin{array}{l}\text { Peripheral vascular } \\
\text { disease }\end{array}$ & 32.5 & 21.9 & 23.6 & 54.5 & $<0.001$ \\
\hline $\begin{array}{l}\text { Heart failure \& } \\
\text { arrhythmia }\end{array}$ & 44.2 & 20.9 & 29.9 & 49.2 & $<0.001$ \\
\hline Diabetes & 28.0 & 20.3 & 21.8 & 58.0 & $<0.001$ \\
\hline Infectious diseases $^{\ddagger}$ & 47.9 & 20.2 & 22.5 & 57.3 & $<0.001$ \\
\hline Respiratory failure & 23.1 & 20.0 & 37.6 & 42.4 & $<0.001$ \\
\hline
\end{tabular}




\begin{tabular}{|c|c|c|c|c|c|}
\hline Anemia & 42.1 & 19.6 & 24.2 & 56.3 & $<0.001$ \\
\hline Other blood diseases & 16.3 & 19.1 & 29.5 & 51.4 & $<0.001$ \\
\hline Thyroid disorders & 30.6 & 18.9 & 17.4 & 63.7 & $<0.001$ \\
\hline Arthritis \& arthropathy & 58.6 & 18.5 & 16.4 & 65.1 & $<0.001$ \\
\hline Ischemic heart disease & 49.8 & 18.5 & 23.0 & 58.6 & $<0.001$ \\
\hline Back/neck pain & 50.9 & 18.2 & 16.3 & 65.5 & $<0.001$ \\
\hline COPD \& related diseases & 49.6 & 17.4 & 21.7 & 61.0 & $<0.001$ \\
\hline Hypertension & 75.2 & 17.0 & 18.8 & 64.2 & $<0.001$ \\
\hline Respiratory diseases & 71.8 & 16.9 & 21.4 & 61.7 & $<0.001$ \\
\hline $\begin{array}{l}\text { Other circulatory } \\
\text { diseases }\end{array}$ & 76.1 & 16.8 & 20.9 & 62.3 & $<0.001$ \\
\hline $\begin{array}{l}\text { Acute renal failure \& } \\
\text { insufficiency }\end{array}$ & 4.7 & 16.8 & 60.8 & 22.5 & $<0.001$ \\
\hline $\begin{array}{l}\text { Other metabolic \& } \\
\text { immunity disorders }\end{array}$ & 70.7 & 16.6 & 19.5 & 64.0 & $<0.001$ \\
\hline $\begin{array}{l}\text { Musculoskeletal } \\
\text { disorders }\end{array}$ & 84.5 & 16.5 & 18.8 & 65.8 & $<0.001$ \\
\hline Gastrointestinal diseases & 73.1 & 16.3 & 20.1 & 63.7 & $<0.001$ \\
\hline Colorectal \& lung cancer & 7.7 & 16.3 & 43.7 & 40.0 & $<0.001$ \\
\hline Glaucoma \& cataract & 70.9 & 16.2 & 15.5 & 68.4 & $<0.001$ \\
\hline Genitourinary diseases & 77.2 & 16.1 & 18.8 & 65.1 & $<0.001$ \\
\hline Other cancers & 60.7 & 14.8 & 19.6 & 65.6 & 0.14 \\
\hline Breast \& prostate cancer & 13.0 & 13.4 & 22.4 & 64.2 & 0.006 \\
\hline No Condition (no claims) & 5.4 & 9.0 & 16.1 & 74.9 & 0.001 \\
\hline
\end{tabular}

${ }^{\dagger}$ Respondents are consider to have the condition if there was at least one inpatient claim or 2 non-hospital claims (outpatient, home health, SNF or hospice) with a primary or secondary diagnosis of interest between Jan 1, 1992 to December 31, 1999

${ }^{\ddagger}$ Not including pneumonia, acute respiratory infections or influenza All percentages based on weighted sample size. Statistical tests account for complex survey design. Conditions are ordered based on strength of their relationship with disability.

$C O P D=$ chronic obstructive pulmonary disease 
Table 2. Multinomial Regression Estimates of the Association between Clinical Conditions and Any, Mobility, Complex Task and Self-Care Disability

\begin{tabular}{|c|c|c|c|c|}
\hline Variable & $\begin{array}{l}\text { Any Disability } \\
\text { vs. Health } \\
\text { Coefficient } \\
\text { (SE) }\end{array}$ & $\begin{array}{l}\text { Mobility } \\
\text { Disabled vs. } \\
\text { Healthy } \\
\text { Coefficient } \\
\text { (SE) }\end{array}$ & $\begin{array}{l}\text { Complex } \\
\text { Task } \\
\text { Disabled vs. } \\
\text { Healthy } \\
\text { Coefficient } \\
\text { (SE) }\end{array}$ & $\begin{array}{l}\text { Self-care } \\
\text { Disabled vs. } \\
\text { Healthy } \\
\text { Coefficient } \\
\text { (SE) }\end{array}$ \\
\hline \multicolumn{5}{|l|}{ Diseases/Conditions } \\
\hline $\begin{array}{l}\text { Dementia \& organic brain } \\
\text { diseases }\end{array}$ & $2.08(0.28)^{* *}$ & $2.00(0.28)^{* *}$ & $2.67(0.29)^{* *}$ & $1.79(0.28)^{* *}$ \\
\hline $\begin{array}{l}\text { Paralysis, Parkinson's and related } \\
\text { diseases }\end{array}$ & $0.84(0.14)^{* *}$ & $0.98(0.15)^{* *}$ & $1.14(0.14)^{* *}$ & $1.07(0.13)^{* *}$ \\
\hline Hip \& pelvic fracture & $0.76(0.15)^{* *}$ & $0.75(0.16)^{* *}$ & $0.58(0.17)^{* *}$ & $0.90(0.17)^{* *}$ \\
\hline Colorectal \&/or lung cancer & $0.62(0.14)^{* *}$ & $0.61(0.16)^{* *}$ & $0.63(0.18)^{* *}$ & $0.53(0.17)^{* *}$ \\
\hline Acute renal failure \& insufficiency & $0.54(0.24) * *$ & $0.58(0.26)^{* *}$ & $0.74(0.25)^{* *}$ & $0.47(0.24)^{* *}$ \\
\hline Heart failure \& arrhythmia & $0.48(0.19) * *$ & $0.41(0.20)^{* *}$ & $0.99(0.27)^{* *}$ & $0.44(0.23)^{*}$ \\
\hline Arthritis \& arthropathy & $0.40(0.18) * *$ & $0.44(0.19)^{* *}$ & $0.71(0.24)^{* *}$ & $0.56(0.22)^{* *}$ \\
\hline Respiratory failure & $0.38(0.09)^{* *}$ & $0.37(0.11)^{* *}$ & $0.43(0.12)^{* *}$ & $0.56(0.11)^{* *}$ \\
\hline Chronic renal failure & $0.32(0.16)^{* *}$ & $0.43(0.17)^{* *}$ & $0.31(0.18)^{*}$ & $0.34(0.17)^{*}$ \\
\hline Depression & $0.30(0.11)^{* *}$ & $0.39(0.12)^{* *}$ & $0.38(0.12)^{* *}$ & $0.33(0.12)^{* *}$ \\
\hline Other mental disorders & $0.27(0.10)^{* *}$ & $0.30(0.11)^{* *}$ & $0.31(0.13)^{* *}$ & $0.23(0.11)^{* *}$ \\
\hline Infectious diseases & $0.22(0.21)$ & $0.41(0.27)$ & $0.65(0.24)^{* *}$ & $0.33(0.24)$ \\
\hline Peripheral vascular disease & $0.14(0.08)^{*}$ & $0.22(0.09)^{* *}$ & $0.20(0.11)^{*}$ & $0.14(0.09)$ \\
\hline Respiratory diseases & $0.14(0.10)$ & $-0.04(0.12)$ & $0.17(0.13)$ & $0.11(0.12)$ \\
\hline Stroke & $0.13(0.22)$ & $0.02(0.25)$ & $-0.10(0.27)$ & $0.39(0.25)$ \\
\hline Anemia & $0.12(0.10)$ & $0.11(0.11)$ & $0.00(0.11)$ & $0.03(0.12)$ \\
\hline Other blood disease & $0.10(0.11)$ & $0.17(0.12)$ & $0.28(0.13)^{* *}$ & $0.04(0.11)$ \\
\hline COPD \& related diseases & $0.05(0.09)$ & $0.09(0.09)$ & $0.06(0.10)$ & $0.02(0.10)$ \\
\hline Back/neck pain & $0.05(0.10)$ & $-0.01(0.09)$ & $-0.02(0.10)$ & $0.02(0.10)$ \\
\hline Hypertension & $0.05(0.12)$ & $0.18(0.13)$ & $0.04(0.14)$ & $0.02(0.12)$ \\
\hline Ischemic heart disease & $0.04(0.09)$ & $0.02(0.10)$ & $-0.02(0.11)$ & $0.12(0.11)$ \\
\hline Musculoskeletal disorders & $-0.01(0.18)$ & $-0.01(0.20)$ & $-0.11(0.21)$ & $0.09(0.21)$ \\
\hline Diabetes & $-0.02(0.22)$ & $0.03(0.25)$ & $0.30(0.28)$ & $-0.06(0.28)$ \\
\hline Genitourinary diseases & $-0.04(0.11)$ & $-0.12(0.12)$ & $-0.15(0.14)$ & $0.03(0.13)$ \\
\hline Thyroid Disorders & $-0.04(0.09)$ & $-0.13(0.09)$ & $-0.11(0.10)$ & $0.01(0.09)$ \\
\hline Breast \&/or prostate cancer & $-0.06(0.13)$ & $0.04(0.13)$ & $-0.16(0.15)$ & $-0.12(0.13)$ \\
\hline $\begin{array}{l}\text { Other metabolic \& immunity } \\
\text { disorders }\end{array}$ & $-0.11(0.13)$ & $-0.20(0.14)$ & $-0.18(0.13)$ & $-0.10(0.13)$ \\
\hline Other circulatory diseases & $-0.13(0.11)$ & $0.07(0.12)$ & $-0.27(0.15)^{*}$ & $-0.18(0.15)$ \\
\hline Gastrointestinal diseases & $-0.20(0.10)^{* *}$ & $-0.30(0.10)^{* *}$ & $-0.15(0.12)$ & $-0.14(0.11)$ \\
\hline Glaucoma \& cataract & $-0.24(0.11)^{* *}$ & $-0.40(0.12)^{* *}$ & $-0.17(0.13)$ & $-0.23(0.11)^{* *}$ \\
\hline Other cancers & $-0.26(0.08)^{* *}$ & $-0.20(0.09)^{* *}$ & $-0.30(0.10)^{* *}$ & $-0.19(0.09)^{* *}$ \\
\hline No diseases or conditions & $0.12(0.26)$ & $0.05(0.32)$ & $0.37(0.28)$ & $0.23(0.29)$ \\
\hline \multicolumn{5}{|l|}{ Interactions } \\
\hline Infectious diseases and diabetes & $0.22(0.19)$ & $0.21(0.19)$ & $0.03(0.22)$ & $0.26(0.22)$ \\
\hline Infectious diseases and dementia & $-0.02(0.19)$ & $-0.06(0.21)$ & $0.02(0.23)$ & $0.21(0.22)$ \\
\hline $\begin{array}{l}\text { Infectious diseases and heart } \\
\text { failure }\end{array}$ & $0.24(0.19)$ & $0.27(0.20)$ & $-0.02(0.23)$ & $0.21(0.21)$ \\
\hline Infectious disease and arthritis & $-0.20(0.19)$ & $-0.28(0.21)$ & $-0.45(0.22)^{* *}$ & $-0.25(0.23)$ \\
\hline
\end{tabular}




\begin{tabular}{|l|c|c|c|c|}
\hline Diabetes and dementia & $-0.23(0.19)$ & $-0.22(0.22)$ & $-0.58(0.21)^{* *}$ & $-0.28(0.24)$ \\
\hline Diabetes and heart failure & $-0.11(0.19)$ & $-0.09(0.22)$ & $-0.28(0.26)$ & $0.09(0.24)$ \\
\hline Diabetes and arthritis & $0.43(0.19)^{* *}$ & $0.47(0.21)^{* *}$ & $0.24(0.24)$ & $0.33(0.27)$ \\
\hline Dementia and heart failure & $-0.50(0.22)^{* *}$ & $-0.48(0.22)^{* *}$ & $-0.60(0.22)^{* *}$ & $-0.22(0.24)$ \\
\hline Dementia and arthritis & $-0.38(0.24)$ & $-0.25(0.27)$ & $-0.38(0.26)$ & $-0.18(0.24)$ \\
\hline Arthritis and heart failure & $-0.07(0.21)$ & $-0.03(0.22)$ & $-0.35(0.27)$ & $-0.14(0.23)$ \\
\hline Stroke and infectious disease & $0.15(0.20)$ & $0.07(0.22)$ & $0.11(0.25)$ & $-0.13(0.22)$ \\
\hline Stroke and diabetes & $0.07(0.19)$ & $0.09(0.21)$ & $0.44(0.24)^{*}$ & $-0.09(0.23)$ \\
\hline Stroke and dementia & $-0.41(0.20)^{* *}$ & $-0.33(0.21)$ & $-0.31(0.20)$ & $-0.44(0.20)^{* *}$ \\
\hline Stroke and heart failure & $0.28(0.18)$ & $0.29(0.21)$ & $0.44(0.22)^{* *}$ & $0.29(0.22)$ \\
\hline Stroke and arthritis & $-0.14(0.18)$ & $0.01(0.20)$ & $-0.16(0.20)$ & $-0.28(0.20)$ \\
\hline Demographic Characteristics in & & & & \\
1994^ & & & & \\
\hline Age70 - 74 & $0.09(0.15)$ & $-0.01(0.17)$ & $0.11(0.19)$ & $0.28(0.17)$ \\
\hline Age75 - 79 & $0.77(0.15)^{* *}$ & $0.77(0.16)^{* *}$ & $0.84(0.18)^{* *}$ & $0.87(0.19)^{* *}$ \\
\hline Age80 - 84 & $1.31(0.16)^{* *}$ & $1.33(0.18)^{* *}$ & $1.46(0.19)^{* *}$ & $1.44(0.21)^{* *}$ \\
\hline Age85 - 89 & $1.74(0.19)^{* *}$ & $1.75(0.20)^{* *}$ & $1.97(0.23)^{* *}$ & $1.76(0.22)^{* *}$ \\
\hline Age90 + & $1.78(0.37)^{* *}$ & $2.02(0.39)^{* *}$ & $2.12(0.40)^{* *}$ & $2.06(0.42)^{* *}$ \\
\hline Widowed & $0.10(0.09)$ & $0.15(0.10)$ & $0.06(0.10)$ & $0.13(0.11)$ \\
\hline Divorced, Separated or Single & $0.45(0.15)^{* *}$ & $0.47(0.16)^{* *}$ & $0.24(0.18)$ & $0.35(0.15)^{* *}$ \\
\hline Missing marital status & $-0.41(0.28)$ & $-0.30(0.28)$ & $-0.33(0.34)$ & $-0.24(0.27)$ \\
\hline Black & $0.04(0.21)$ & $0.10(0.20)$ & $0.28(0.22)$ & $-0.10(0.20)$ \\
\hline Otherrace & $-0.29(0.28)$ & $-0.48(0.38)$ & $0.11(0.40)$ & $-0.08(0.31)$ \\
\hline Female & $0.28(0.09)^{* *}$ & $0.31(0.10)^{* *}$ & $0.06(0.11)$ & $0.22(0.11)^{* *}$ \\
\hline
\end{tabular}

$\wedge$ Reference groups were individuals “age 65 - 69" for age categories, "married” for marital status indicators, and "white" for race variables. Conditions are ordered based on strength of their relationship with overall disability. Standard errors account for complex survey design.

$* 0.05<$ p-value $<0.10$

$* *$ p-value $<0.05$ 
Figure 1: Estimated Percentage of Any New Disability Attributable to Each Condition

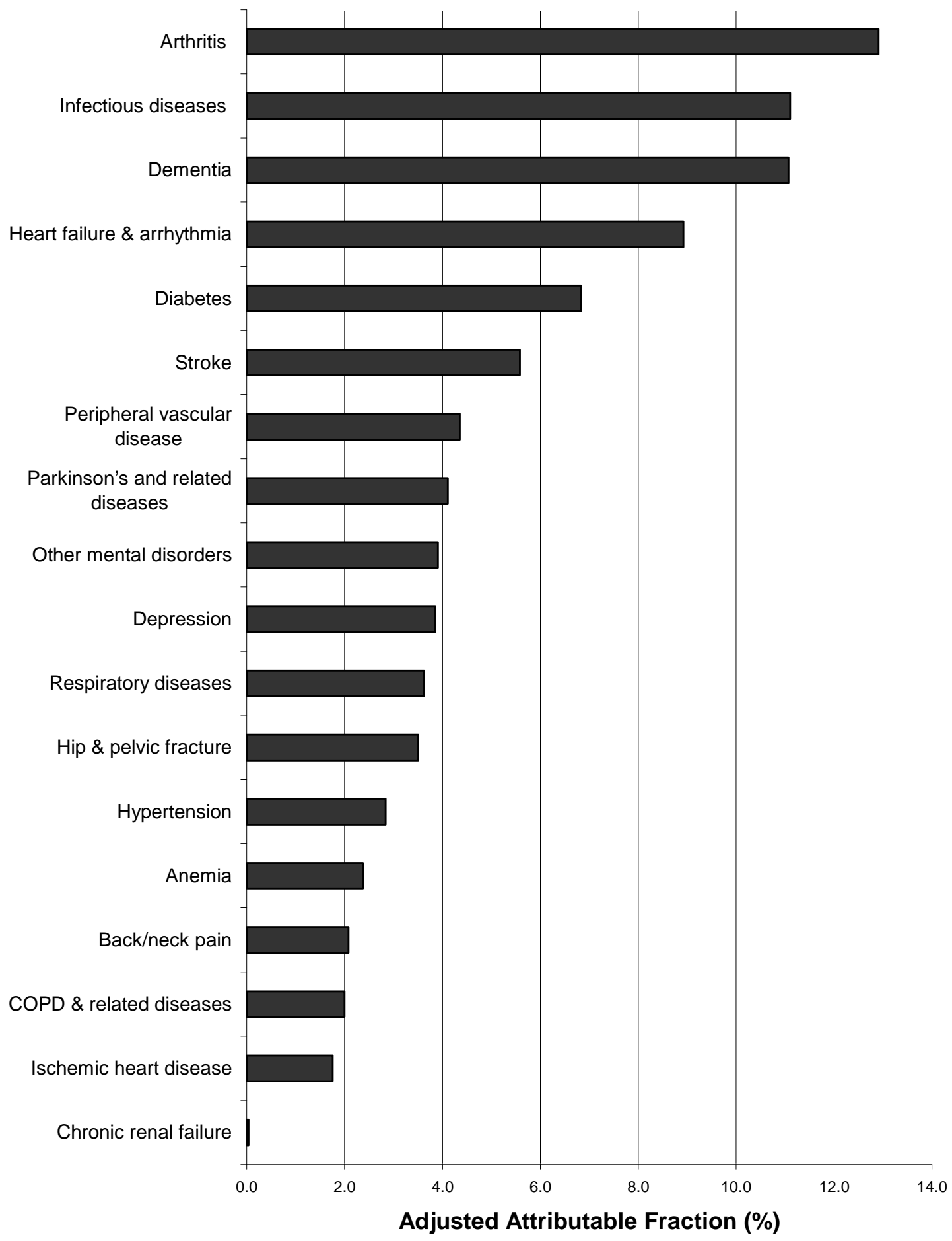


Figure 2: Estimated Percentage of Mobility Disability Attributable to Each Condition

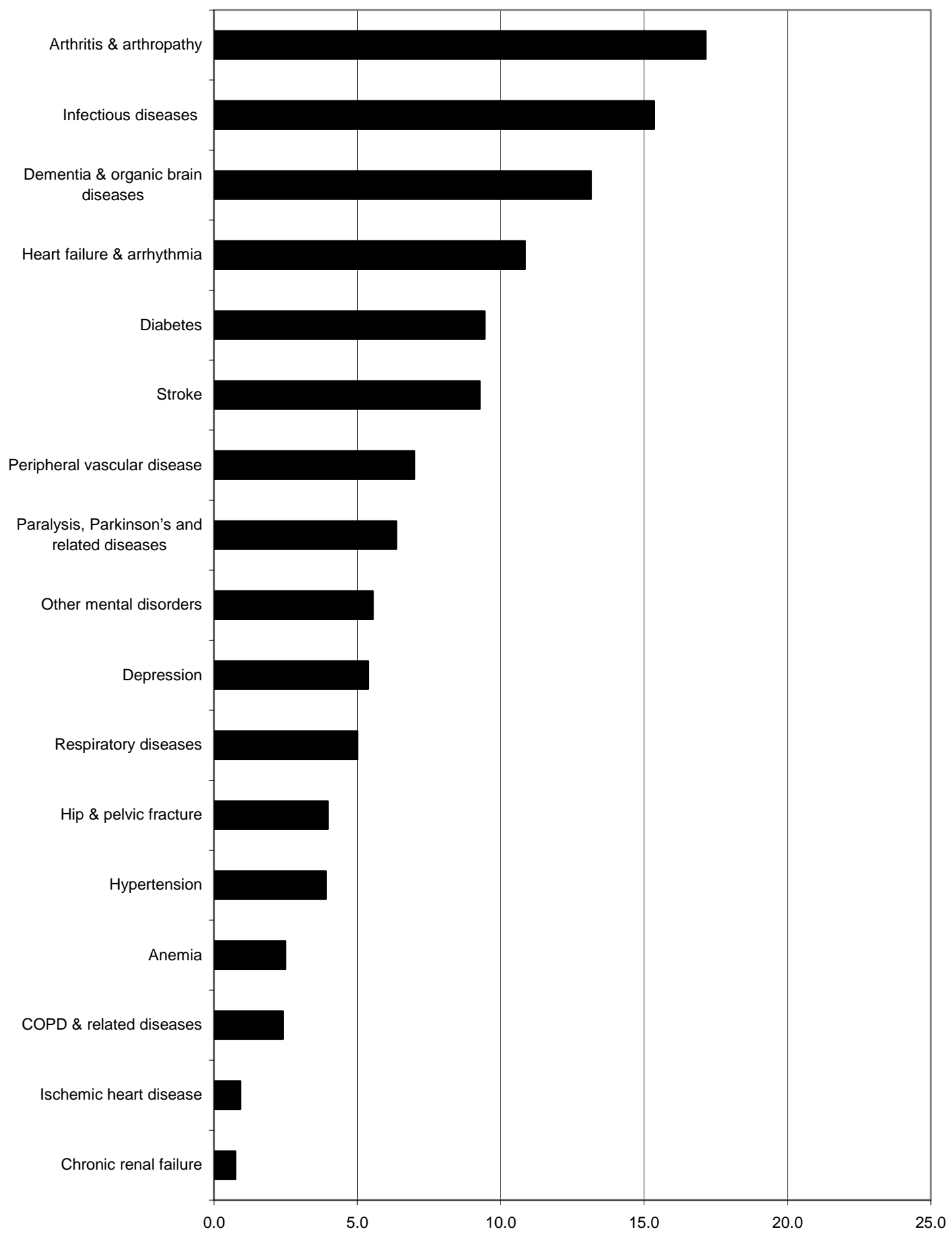


Figure 3: Estimated Percentage of Disability in Complex Tasks Attributable to Each Condition

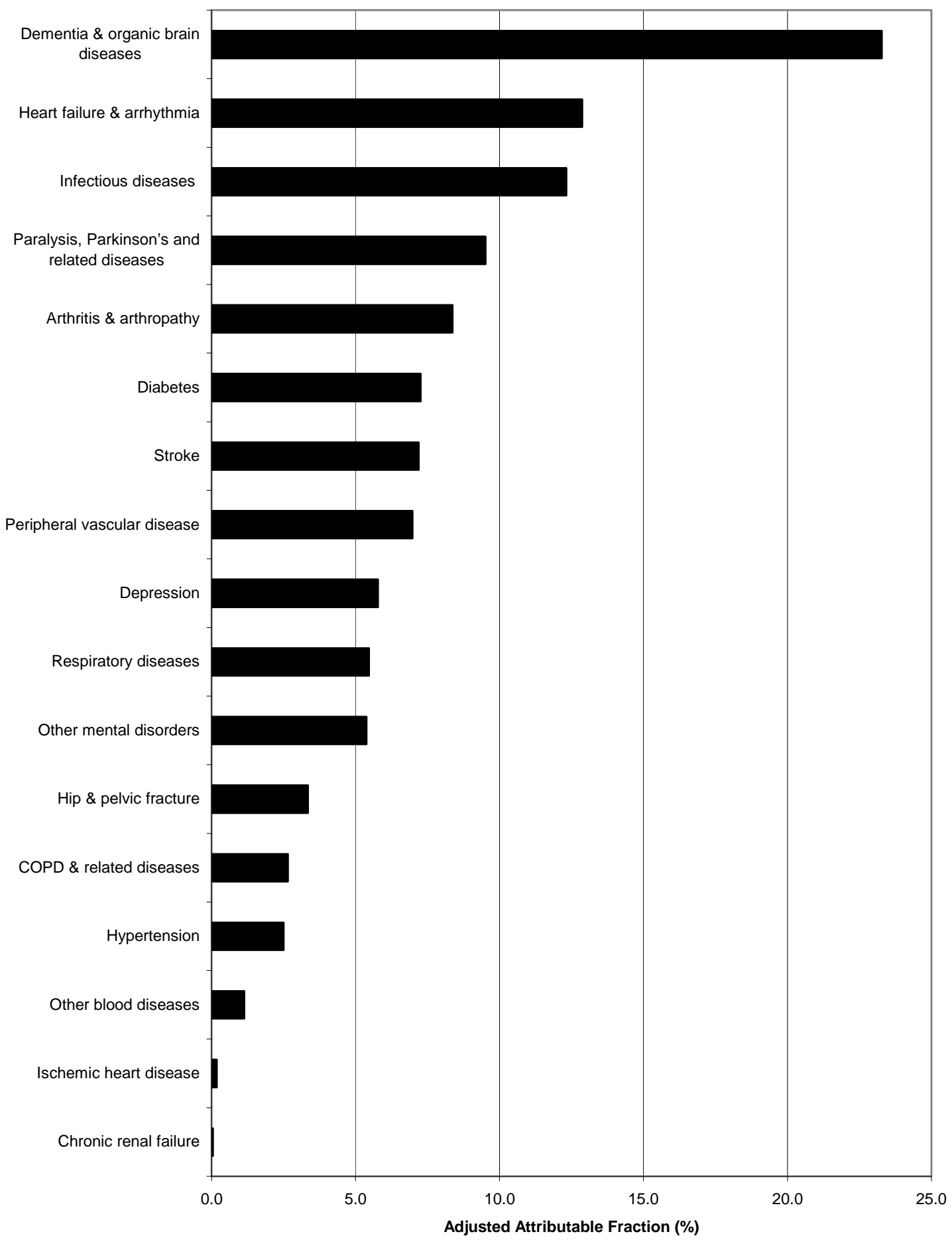


Figure 4: Estimated Percentage of Disability in Self-Care Tasks Attributable to Each Condition

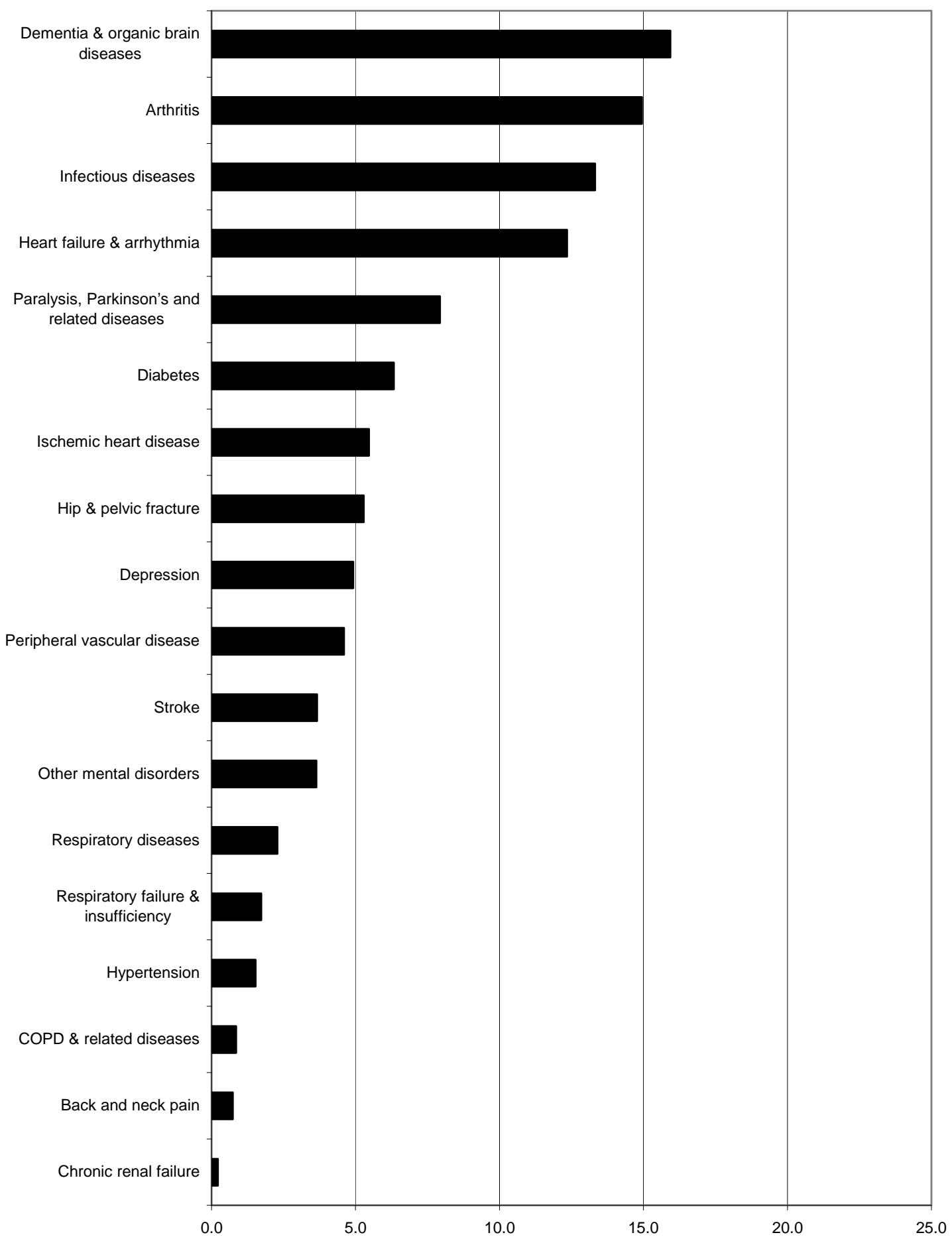


Figure 5: Number of Limitations among Newly Disabled Respondents by Conditions in Medical Claims

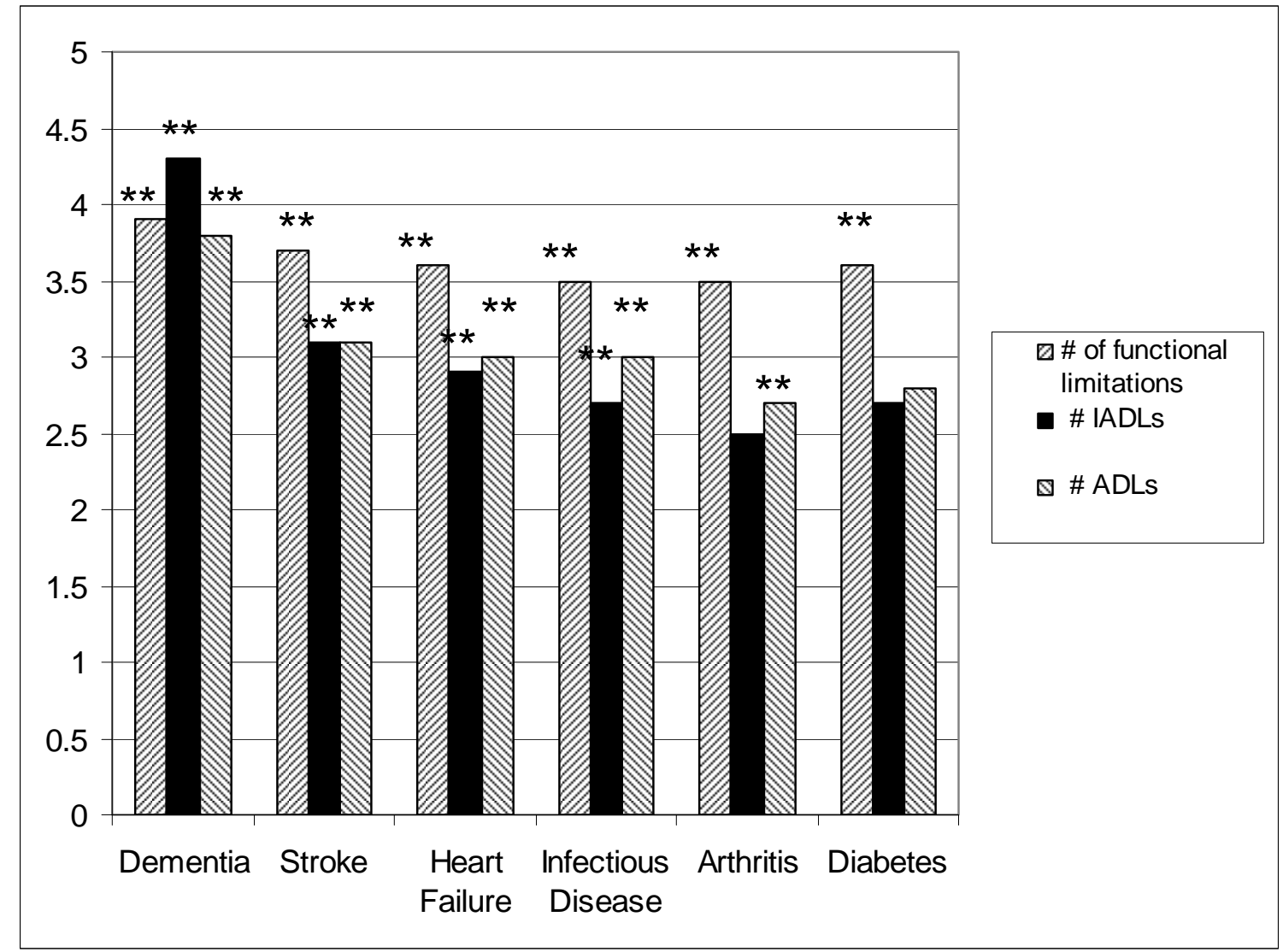

* Marginally significantly different from respondents without evidence of condition in their medical claims $(0.05<$ p-value $<0.10)$

** Significantly different from respondents without evidence of condition in their medical claims (p-value $<0.05)$

Institutionalized respondents are excluded from calculations of average numbers of functional limitations and IADLs tasks. 
Table 3: Self-reported Utilization of Health and Assistive Services by Conditions in Medical Claims

\begin{tabular}{|c|c|c|c|c|c|c|c|}
\hline & $\begin{array}{l}\text { All } \\
\text { Newly } \\
\text { Disabled } \\
\end{array}$ & Dementia & Stroke & $\begin{array}{l}\text { Heart } \\
\text { Failure } \\
\end{array}$ & $\begin{array}{l}\text { Infectious } \\
\text { Disease } \\
\end{array}$ & Arthritis & Diabetes \\
\hline $\mathbf{N}$ & 1264 & 450 & 598 & 781 & 808 & 911 & 449 \\
\hline \% of Cohort & 100 & 34.2 & 46.4 & 61.2 & 63.8 & 71.7 & 37.5 \\
\hline $\begin{array}{l}\text { Institutionalized (at } \\
\text { time of survey) }\end{array}$ & 20.3 & $45.9 * *$ & $26.9 * *$ & $23.1^{* *}$ & $26.1^{* *}$ & 21.2 & 21.2 \\
\hline $\begin{array}{l}\text { Hospitalization (in the } \\
\text { past year) }\end{array}$ & 37.1 & $42.9 * *$ & $47.2^{* *}$ & $45.6 * *$ & $42.1 * *$ & $39.4^{* *}$ & $42.8 * *$ \\
\hline \multicolumn{8}{|l|}{ Of those in community: } \\
\hline $\begin{array}{l}\text { Past nursing home } \\
\text { stay (ever) }\end{array}$ & 11.8 & $18.3^{* *}$ & $15.5^{* *}$ & $14.0^{* *}$ & $14.8 * *$ & 11.5 & 11.5 \\
\hline $\begin{array}{l}\text { Assisted living (at time } \\
\text { of survey) }\end{array}$ & 2.8 & $5.6^{* *}$ & 3.4 & 2.5 & 2.5 & $2.0 * *$ & 3.5 \\
\hline $\begin{array}{l}\text { Home health care (in } \\
\text { the past month) }\end{array}$ & 11.7 & $20.1^{* *}$ & $15.3^{* *}$ & $15.6^{* *}$ & $13.9 * *$ & 11.9 & 13.8 \\
\hline $\begin{array}{l}\text { Physical, occupational, } \\
\text { speech or hearing } \\
\text { therapy (in the past } \\
\text { month) }\end{array}$ & 8.4 & $11.8^{* *}$ & $12.2^{* *}$ & 8.5 & 9.5 & 8.9 & 8.1 \\
\hline $\begin{array}{l}\text { Emergency room visit } \\
\text { (in the past month) }\end{array}$ & 6.6 & 5.7 & 6.4 & $8.3^{* *}$ & 6.3 & 6.2 & 7.2 \\
\hline $\begin{array}{l}\text { Physician visit (in the } \\
\text { past month) }\end{array}$ & 49.8 & $44.8^{*}$ & 51.5 & 52.2 & 49.7 & $52.1^{* *}$ & 53.4 \\
\hline $\begin{array}{l}\text { Number of } \\
\text { prescriptions (in the } \\
\text { past month) }\end{array}$ & 3.9 & $3.5^{*}$ & $4.5^{* *}$ & $4.7^{* *}$ & $4.4^{* *}$ & $4.1^{* *}$ & $4.7 * *$ \\
\hline
\end{tabular}

* Marginally significantly different from respondents without evidence of condition in their medical claims $(0.05<$ p-value $<0.10)$

** Significantly different from respondents without evidence of condition in their medical claims (p-value $<0.05)$ 
Table 4. Self-reported causes of disability among the newly disabled cohort residing in the community $(\mathrm{N}=\mathbf{8 9 2})$

\begin{tabular}{|c|c|c|}
\hline Cause & $\mathbf{N}^{\dagger}$ & $\%$ \\
\hline Chronic Condition & 489 & $54.8 \%$ \\
\hline Arthritis & 186 & $22.2 \%$ \\
\hline Heart or circulatory disease (not including heart failure) & 91 & $10.0 \%$ \\
\hline Dementia/memory problems & 88 & $9.2 \%$ \\
\hline Lung disease (asthma, emphysema) & 38 & $4.7 \%$ \\
\hline Diabetes & 36 & $3.9 \%$ \\
\hline Eye disease (cataract, glaucoma, macular degeneration) & 38 & $3.6 \%$ \\
\hline Cancer & 30 & $3.4 \%$ \\
\hline Heart failure & 23 & $2.8 \%$ \\
\hline Osteoporosis & 19 & $2.4 \%$ \\
\hline Hypertension & 21 & $2.4 \%$ \\
\hline Parkinson's & 14 & $1.7 \%$ \\
\hline Depression/other mental illness & 6 & $0.7 \%$ \\
\hline Back disease & 6 & $0.4 \%$ \\
\hline Other chronic condition & 64 & $8.0 \%$ \\
\hline Acute Event & 275 & $32.1 \%$ \\
\hline Stroke & 83 & $10.1 \%$ \\
\hline AMI or bypass surgery & 42 & $5.4 \%$ \\
\hline Hip/knee replacement & 40 & $4.1 \%$ \\
\hline Other surgery & 33 & $4.6 \%$ \\
\hline Hip fracture & 36 & $3.6 \%$ \\
\hline Other fracture or fall & 42 & $4.0 \%$ \\
\hline Amputation & 7 & $1.0 \%$ \\
\hline Other acute event & 34 & $3.9 \%$ \\
\hline Symptom not linked to condition & 266 & $30.2 \%$ \\
\hline Pain/Discomfort (includes pain, swelling, stiffness and other problems) & 105 & $11.8 \%$ \\
\hline Hips/knees & 44 & $5.1 \%$ \\
\hline Back & 30 & $3.4 \%$ \\
\hline Legs & 25 & $3.0 \%$ \\
\hline Feet/ankle & 13 & $1.5 \%$ \\
\hline Upper extremities & 4 & $0.4 \%$ \\
\hline Other pain/discomfort & 6 & $0.8 \%$ \\
\hline Balance & 40 & $4.4 \%$ \\
\hline Unsteady/balance problems & 31 & $3.4 \%$ \\
\hline Dizziness & 12 & $1.5 \%$ \\
\hline Endurance & 22 & $2.8 \%$ \\
\hline Shortness of breath & 15 & $2.0 \%$ \\
\hline Fatigue & 8 & $0.9 \%$ \\
\hline Weakness & 37 & $3.7 \%$ \\
\hline General weakness & 23 & $2.2 \%$ \\
\hline Lower body weakness & 14 & $1.4 \%$ \\
\hline Other Symptoms & 105 & $12.3 \%$ \\
\hline Vision/blindness & 48 & $5.6 \%$ \\
\hline Hearing & 16 & $2.0 \%$ \\
\hline Fear/security & 9 & $1.1 \%$ \\
\hline Other symptom & 38 & $4.3 \%$ \\
\hline Old Age & 133 & $14.0 \%$ \\
\hline
\end{tabular}

Respondents were able to list up to 10 causes for their disability. N represents the number of respondents who reported the condition or symptom as at least one cause of their disability. All percentages based on weighted sample size 
Table 5: Chronic condition cited by Community-Dwelling Newly Disabled Respondents who also Cite Symptoms or Old Age as a Cause of Their Disability.

\begin{tabular}{|l||c|c|c|}
\hline & $\begin{array}{c}\text { All Newly } \\
\text { Disabled }\end{array}$ & Old Age & Symptom \\
\hline $\mathbf{N}$ & 892 & 133 & 266 \\
\hline \% of Cohort & 100 & 14.0 & 30.2 \\
\hline \hline Chronic conditions & 54.8 & 32.8 & 43.5 \\
\hline Arthritis & 22.2 & 17.1 & 12.0 \\
\hline Heart disease & 12.5 & 6.1 & 15.7 \\
\hline Lung disease & 4.7 & 3.1 & 5.5 \\
\hline Dementia & 9.2 & 6.2 & 4.8 \\
\hline Diabetes & 3.9 & 1.5 & 5.4 \\
\hline Eye disease & 3.6 & 0.0 & 2.6 \\
\hline \hline Acute conditions & 32.1 & 12.8 & 20.5 \\
\hline Hip fracture & 3.6 & 0.9 & 2.5 \\
\hline Heart attack or open heart surgery & 5.4 & 4.2 & 3.2 \\
\hline Stroke & 10.1 & 4.6 & 5.9 \\
\hline Old Age & 14.0 & 100.0 & 8.4 \\
\hline Old age only & 6.5 & 46.0 & 0.0 \\
\hline \hline Symptom & 30.2 & 18.1 & 100.0 \\
\hline Symptom only & 12.5 & 0.0 & 41.4 \\
\hline Pain & 11.8 & 2.0 & 39.2 \\
\hline Balance & 4.4 & 1.4 & 15.5 \\
\hline Endurance & 2.8 & 5.0 & 9.1 \\
\hline Weakness & 3.7 & 5.4 & 12.1 \\
\hline Other Symptom & 12.3 & 7.2 & 40.8 \\
\hline
\end{tabular}


Table 6: Characteristics of Newly Disabled Cohort According to Self-Reported Cause of Disability.

\begin{tabular}{|c|c|c|c|c|c|c|c|}
\hline & $\begin{array}{c}\text { Medical } \\
\text { only }^{\dagger}\end{array}$ & $\begin{array}{l}\text { Old } \\
\text { Age }\end{array}$ & Symptom & Pain & Balance & Endurance & Weakness \\
\hline $\mathbf{N}$ & 518 & 133 & 266 & 105 & 40 & 22 & 37 \\
\hline$\%$ of cohort & 58.3 & 14.0 & 30.2 & 11.8 & 4.4 & 2.8 & 3.7 \\
\hline Average Age & 75.8 & $80.2 * *$ & 76.4 & 76.3 & 76.2 & 77.2 & 77.0 \\
\hline Female & 63.5 & $71.5^{*}$ & 67.2 & 68.2 & 55.4 & 61.2 & $88.7 * *$ \\
\hline Race & & * & & & & & \\
\hline White & 92.9 & 87.3 & 95.0 & 96.3 & 90.7 & 96.1 & 85.0 \\
\hline Black & 6.0 & 9.6 & 4.4 & 3.2 & 9.3 & 3.9 & 11.3 \\
\hline Other & 1.1 & 3.1 & 0.6 & 0.4 & 0.0 & 0.0 & 3.8 \\
\hline \multicolumn{8}{|l|}{$\begin{array}{l}\text { Marital Status } \\
\text { (1994) }\end{array}$} \\
\hline Married & 51.5 & 45.1 & 50.9 & 43.7 & 55.8 & 55.8 & 34.1 \\
\hline Widowed & 37.2 & 43.0 & 36.3 & 44.5 & 30.5 & 28.4 & 44.1 \\
\hline Not Married & 10.1 & 10.5 & 11.1 & 11.8 & 10.3 & 7.2 & 21.7 \\
\hline Missing & 1.3 & 1.5 & 1.6 & 0.0 & 3.4 & 8.6 & 0.0 \\
\hline $\begin{array}{l}\text { Marital Status } \\
\text { (1999) }\end{array}$ & & $* *$ & & & & & \\
\hline Married & 39.6 & 26.6 & 39.1 & 33.0 & 49.9 & 47.0 & 30.4 \\
\hline Widowed & 51.8 & 68.8 & 52.1 & 57.3 & 44.1 & 37.3 & 63.4 \\
\hline Not Married & 8.6 & 3.7 & 8.7 & 9.7 & 5.9 & 15.8 & 6.3 \\
\hline \multicolumn{8}{|c|}{ \% with conditions/diseases ${ }^{\ddagger}$ : } \\
\hline $\begin{array}{l}\text { Arthritis \& } \\
\text { arthropathy }\end{array}$ & 74.5 & $61.6^{* *}$ & 69.9 & $80.9 * *$ & 59.8 & 67.4 & 71.9 \\
\hline $\begin{array}{l}\text { Infectious } \\
\text { disease }\end{array}$ & 61.1 & 51.1 & 58.1 & 63.7 & 47.4 & 54.2 & 42.4 \\
\hline $\begin{array}{l}\text { Dementia \& } \\
\text { organic brain } \\
\text { diseases }\end{array}$ & 25.3 & 23.8 & $16.4^{* *}$ & $13.2^{* *}$ & 16.5 & 22.4 & $7.0^{\dagger}$ \\
\hline $\begin{array}{l}\text { Heart failure \& } \\
\text { arrhythmia }\end{array}$ & 58.4 & 58.5 & 63.2 & 61.5 & 61.1 & 72.9 & 61.2 \\
\hline Diabetes & 37.3 & $24.8 * *$ & 40.8 & 41.7 & 39.2 & 24.6 & 38.0 \\
\hline Stroke & 43.6 & 40.9 & 42.9 & 44.6 & 50.3 & 43.8 & 39.1 \\
\hline $\begin{array}{l}\text { Peripheral } \\
\text { vascular disease }\end{array}$ & 44.6 & 41.1 & 44.0 & 39.3 & 35.7 & 45.2 & 52.7 \\
\hline $\begin{array}{l}\text { Paralysis, } \\
\text { Parkinson's }\end{array}$ & 22.5 & $9.3^{* *}$ & $12.4^{* *}$ & 12.5 & 15.5 & 16.2 & $3.6^{\dagger}$ \\
\hline Depression & 21.8 & 19.2 & $12.8^{* *}$ & $10.9^{* *}$ & 6.6 & 20.4 & 5.6 \\
\hline $\begin{array}{l}\text { Other mental } \\
\text { disorders }\end{array}$ & 31.7 & 32.1 & 28.7 & 23.6 & 39.3 & 18.3 & 28.6 \\
\hline $\begin{array}{l}\text { Respiratory } \\
\text { diseases }\end{array}$ & 80.5 & $72.2 * *$ & 82.1 & 84.9 & 84.9 & 77.0 & 80.7 \\
\hline $\begin{array}{l}\text { Hip \& pelvic } \\
\text { fracture }\end{array}$ & 14.0 & 11.5 & 9.4 & 9.4 & 6.0 & 14.6 & 7.2 \\
\hline
\end{tabular}

${ }^{\dagger}$ Respondents who reported chronic or acute causes of their disability without citing either symptoms or old age.

* Marginally significantly different from respondents reporting only medical causes $(0.05<$ p-value $<0.10)$

** Significantly different from respondents reporting only medical causes (p-value $<0.05$ )

${ }^{\ddagger}$ Based on diagnoses in respondents medical claims. 
Figure 6: Number of Limitations among Newly Disabled Respondents by Self-reported Cause of Disability

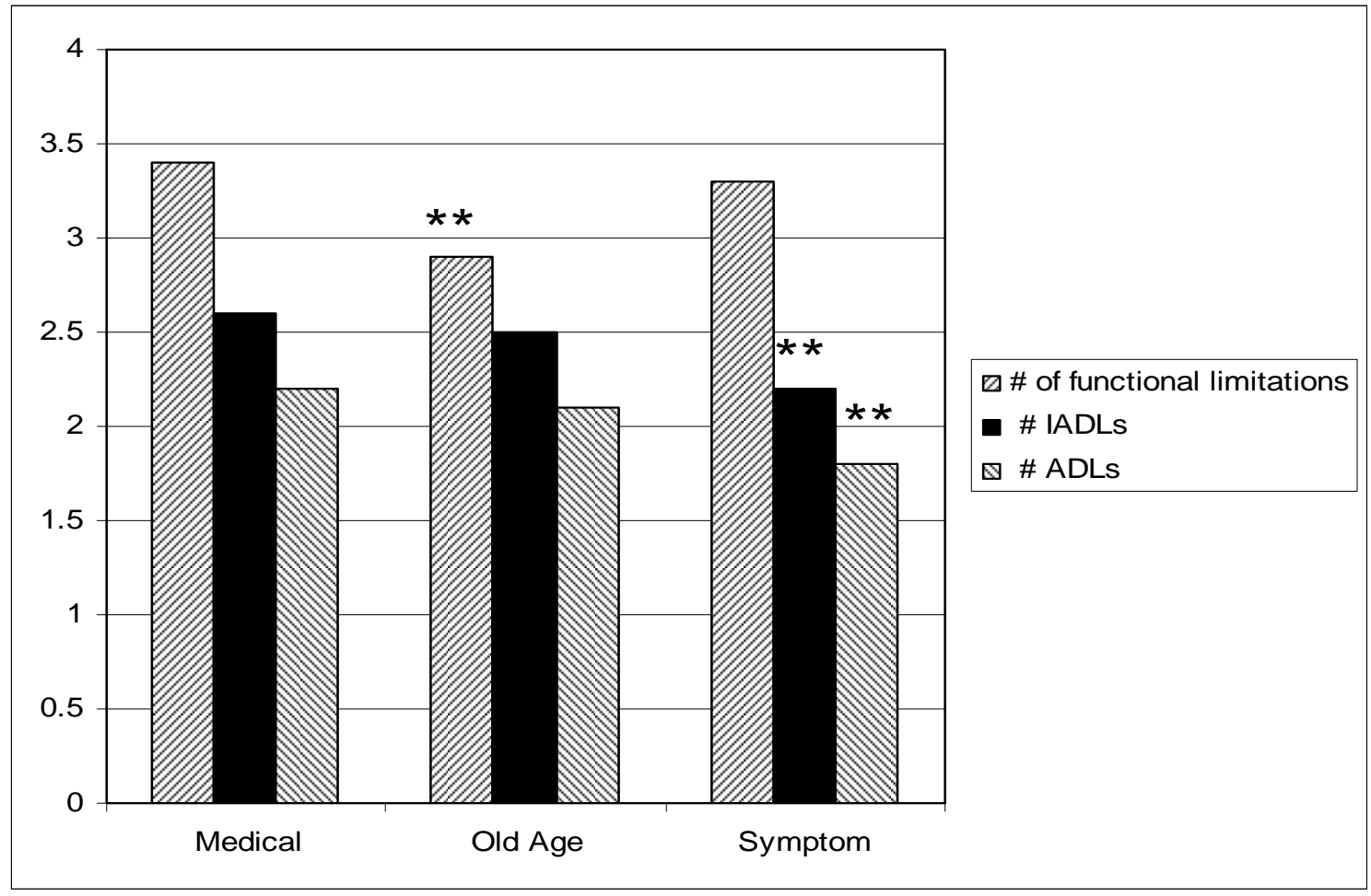

* Marginally significantly different from respondents reporting only medical causes $(0.05<\mathrm{p}$-value $<0.10)$ ** Significantly different from respondents reporting only medical causes ( $\mathrm{p}$-value $<0.05$ ) 
Table 7: Self-reported Utilization of Health and Assistive Services by Self-Reported Cause of Disability

\begin{tabular}{|l||c|c|c||c|c|c|c|c|}
\hline & $\begin{array}{l}\text { Medical } \\
\text { Only }^{\dagger}\end{array}$ & $\begin{array}{l}\text { Old } \\
\text { Age }\end{array}$ & \multicolumn{1}{|c||}{ Symptom } & Pain & Balance & Endurance & Weakness & $\begin{array}{l}\text { Other } \\
\text { Symptom }\end{array}$ \\
\hline N & 518 & 133 & 266 & 105 & 40 & 22 & 37 & 105 \\
\hline \% of cohort & 58.3 & 14.0 & 30.2 & 11.8 & 4.4 & 2.8 & 3.7 & 12.3 \\
\hline $\begin{array}{l}\text { Past nursing home } \\
\text { stay (ever) }\end{array}$ & 15.1 & 9.7 & $6.5^{* *}$ & $5.5^{* *}$ & 8.4 & 4.4 & $4.7 *$ & 9.4 \\
\hline $\begin{array}{l}\text { Assisted living } \\
\text { (now) }\end{array}$ & 3.0 & 3.7 & 2.1 & 2.8 & 4.7 & 0.0 & 0.0 & 3.2 \\
\hline $\begin{array}{l}\text { Home health care } \\
\text { (in the past month) }\end{array}$ & 11.9 & 11.1 & 10.7 & 8.6 & 9.0 & 21.9 & 16.4 & 9.9 \\
\hline $\begin{array}{l}\text { Physical, } \\
\text { occupational, speech } \\
\text { or hearing therapy } \\
\text { (in the past month) }\end{array}$ & 10.3 & 9.3 & $4.9 * *$ & 5.9 & 7.5 & 9.6 & 5.4 & $2.2^{* *}$ \\
\hline $\begin{array}{l}\text { Emergency room } \\
\text { visit (in the past } \\
\text { month) }\end{array}$ & 5.7 & 8.1 & 8.4 & 9.2 & 12.8 & 0.0 & 10.3 & 6.9 \\
\hline $\begin{array}{l}\text { Hospitalization (in } \\
\text { the past year) }\end{array}$ & 36.6 & $25.1^{* *}$ & 36.5 & 36.3 & 37.7 & 30.4 & 34.0 & 39.0 \\
\hline $\begin{array}{l}\text { Physician visit (in } \\
\text { the past month) }\end{array}$ & 52.3 & $41.8^{*}$ & 50.1 & 52.2 & 57.6 & 36.8 & 63.2 & 45.5 \\
\hline $\begin{array}{l}\text { Number of } \\
\text { prescriptions (in the } \\
\text { past month) }\end{array}$ & 4.2 & $3.0^{* *}$ & 3.7 & 3.6 & $3.3 *$ & 3.5 & 4.2 & 3.7 \\
\hline
\end{tabular}

${ }^{\dagger}$ Respondents who reported chronic or acute causes of their disability without citing either symptoms or old age.

* Marginally significantly different from respondents reporting only medical causes $(0.05<$ p-value $<0.10)$

** Significantly different from respondents reporting only medical causes ( $\mathrm{p}$-value $<0.05$ ) 


\section{Appendix}

Table A1. Clinical Conditions

\begin{tabular}{|c|c|c|}
\hline No. & Condition & ICD-9-CM Codes \\
\hline 1 & Infectious diseases & 001.*-139.*, 320.*-323.*, V09.* \\
\hline 2 & Colorectal \& lung cancer & 153.*, 154.*, $162 .^{*}$ \\
\hline 3 & Breast \& prostate cancer & 174.*-175.*, $185 .^{*}$ \\
\hline 4 & Other cancers & 140.*-239.* ( \#2,\#3), 611.72, V10 \\
\hline 5 & Diabetes & $250 . *, 251.3$ \\
\hline 6 & Thyroid disorders & $240 . *-259 . *(\sim \# 5)$ \\
\hline 7 & $\begin{array}{l}\text { Other metabolic \& } \\
\text { immunity disorders }\end{array}$ & $270 . *-273 . *, 275 . *-279 . *$ \\
\hline 8 & Anemia & $280 . *-285 . *$ \\
\hline 9 & Other blood diseases & $285 . *-289 . *$ \\
\hline 10 & $\begin{array}{l}\text { Dementia \& organic brain } \\
\text { diseases }\end{array}$ & 290.*, 294.*, 310.*, 330.*, 331.* \\
\hline 11 & Depression & 296.* ( 296.9), 298.0, 300.4, 311.* \\
\hline 12 & Other mental disorders & 290.*-319.* ( \#10,\#11), 797.* \\
\hline 13 & $\begin{array}{l}\text { Paralysis, Parkinsons's and } \\
\text { related diseases }\end{array}$ & 332.*, 340.*-344.*, 438.* \\
\hline 14 & Stroke & 362.34, 430.*, 431.*, 432.9, 433.*-436.* \\
\hline 15 & Glaucoma \& cataract & 365.*-366.*, 743.2-743.3 \\
\hline 16 & Chronic renal failure & $\begin{array}{l}\text { 403.01, 403.11, 403.91, 404.02, 404.12, 404.92, 585.*-586.*, V45.1, } \\
\text { V56.* }\end{array}$ \\
\hline 17 & Hypertension & 401.*-405.* ( \#16), 437.0, 437.9 \\
\hline 18 & Ischemic heart disease & 410.*-414.* ( 414.11, 414.19), 429.5-429.7 \\
\hline 19 & Heart failure \& arrhythmia & 425.*, 427.1, 427.3-427.5, 428.*, 429.1, 429.3 \\
\hline 20 & Peripheral vascular disease & $\begin{array}{l}\text { 440.*, 442.*, 443.* ( 443.2), 444.*, 446.*, 447.* ( 447.6), 451.*, } \\
\text { 453.1 }\end{array}$ \\
\hline 21 & Other circulatory diseases & 391.*-459.* ( \#13,\#14,\#16,\#17,\#18,\#19,\#20), 786.5, V717.* \\
\hline 22 & \begin{tabular}{|l|} 
Chronic obstructive \\
pulmonary diseases \& \\
related diseases
\end{tabular} & 466.*, 490.*-496.*, 518.12 \\
\hline 23 & Respiratory failure & 518.*, 799.1 \\
\hline 24 & Respiratory diseases & 460.*-519.* ( \#22,\#23), 786.0, 786.1, 786.52, 793.1 \\
\hline 25 & Gastrointestinal disease & $530 . *-579 . *, 789.0,787.0,787.7$ \\
\hline 26 & $\begin{array}{l}\text { Acute renal failure \& } \\
\text { insufficiency }\end{array}$ & 584.*, 587.*, 588.* \\
\hline 27 & Genitourinary diseases & $\begin{array}{l}\text { 580.*-629.* ( \#4,\#16,\#25,\#26), 788.* ( 788.3,788.4), 793.8, V44.5- } \\
\text { V44.6, V55.5-V55.6 }\end{array}$ \\
\hline 28 & Arthritis \& arthropathy & 274.*, 390.*, 710.*-716.* \\
\hline 29 & Back/neck pain & 720.*-724.*, 839.0-839.5, 846.*, 847.* \\
\hline 30 & Hip \& pelvic fracture & 808.*, 820.* \\
\hline 31 & Musculoskeletal disorders & 717.*-739.* ( \#29), 800.*-999.* ( \#29,\#30) \\
\hline
\end{tabular}


Table A2: Self-reported Limitations in Newly Disabled Cohort according to Conditions in their Medical Claims

\begin{tabular}{|l|c|c|c|c|c|c|c|}
\hline & $\begin{array}{c}\text { All } \\
\text { Newly } \\
\text { Disabled } \\
(\mathrm{n}=1264)\end{array}$ & Dementia & Stroke & $\begin{array}{c}\text { Heart } \\
\text { Failure }\end{array}$ & $\begin{array}{c}\text { Infectious } \\
\text { Disease }\end{array}$ & Arthritis & Diabetes \\
\hline & $(\mathrm{n}=598)$ & $(\mathrm{n}=781)$ & $(\mathrm{n}=808)$ & $(\mathrm{n}=911)$ & $(\mathrm{n}=449)$ \\
\hline Functional limitations (among non-institutionalized) \\
\hline Going up stairs & 78.9 & 84.1 & 82.2 & 84.4 & 81.5 & 81.5 & 85.3 \\
\hline Walking across room & 41.1 & 51.0 & 46.1 & 45.1 & 43.8 & 42.7 & 46.6 \\
\hline Bending & 52.9 & 59.1 & 59.4 & 56.7 & 56.2 & 56.7 & 58.7 \\
\hline Lifting 10-lb package & 62.4 & 72.8 & 70.3 & 67.7 & 67.0 & 64.0 & 67.0 \\
\hline Reaching above head & 36.6 & 43.9 & 44.0 & 40.9 & 39.7 & 38.4 & 39.3 \\
\hline Grasping small objects & 32.7 & 38.9 & 36.5 & 34.8 & 35.1 & 33.3 & 34.9 \\
\hline Seeing to read newsprint & 20.2 & 25.7 & 24.7 & 21.9 & 22.5 & 20.9 & 22.5 \\
\hline Speaking & 2.0 & 3.4 & 3.8 & 2.4 & 2.6 & 1.7 & 1.8 \\
\hline Hearing & 6.5 & 14.2 & 6.5 & 6.1 & 6.6 & 7.1 & 8.3 \\
\hline IADLs (among non-institutionalized) & \multicolumn{7}{|l|}{} \\
\hline Light housework & 22.4 & 40.9 & 30.9 & 27.0 & 25.2 & 22.1 & 25.9 \\
\hline Laundry & 27.9 & 51.6 & 37.0 & 32.6 & 31.1 & 28.7 & 29.8 \\
\hline Cooking & 24.3 & 52.6 & 32.2 & 28.9 & 26.8 & 24.1 & 25.8 \\
\hline Grocery shopping & 42.6 & 63.4 & 52.3 & 48.5 & 45.9 & 41.3 & 45.7 \\
\hline Managing money & 23.1 & 54.6 & 30.1 & 24.9 & 23.4 & 22.0 & 22.0 \\
\hline Taking medications & 28.6 & 57.1 & 38.1 & 33.7 & 30.6 & 27.1 & 31.9 \\
\hline Using telephone & 12.7 & 32.2 & 15.7 & 14.1 & 12.3 & 11.9 & 10.3 \\
\hline Getting around outside & 72.9 & 76.6 & 78.2 & 76.3 & 76.9 & 75.4 & 79.8 \\
\hline ADLs (all respondents) & 18.4 & 37.3 & 25.6 & 22.0 & 22.6 & 17.7 & 17.6 \\
\hline Eating & 45.2 & 65.8 & 55.8 & 50.8 & 50.8 & 47.6 & 50.6 \\
\hline Getting out of bed & 55.3 & 69.7 & 65.2 & 62.0 & 60.8 & 59.1 & 59.0 \\
\hline Getting around inside & 33.4 & 62.2 & 43.6 & 39.8 & 40.5 & 35.2 & 37.9 \\
\hline Dressing & 67.2 & 81.5 & 74.0 & 72.5 & 71.7 & 69.0 & 69.0 \\
\hline Bathing & 42.8 & 63.6 & 50.4 & 48.7 & 50.1 & 45.8 & 43.7 \\
\hline Toileting & \multicolumn{7}{|l|}{} \\
\hline
\end{tabular}


Table A3: Self-reported Limitations in Community Dwelling Newly Disabled Cohort according to Self-Reported Cause of Disability

\begin{tabular}{|c|c|c|c|c|c|c|c|c|c|}
\hline & $\begin{array}{c}\text { All } \\
\text { Newly } \\
\text { Disabled }\end{array}$ & $\begin{array}{c}\text { Medical } \\
\text { only }\end{array}$ & $\begin{array}{l}\text { Old } \\
\text { Age }\end{array}$ & Symptom & Pain & Balance & Endurance & Weakness & $\begin{array}{c}\text { Other } \\
\text { Symptom }\end{array}$ \\
\hline & $(n=892)$ & $(n=518)$ & $(n=133)$ & $(n=266)$ & $(n=105)$ & $(n=40)$ & $(n=22)$ & $(n=37)$ & $(n=105)$ \\
\hline \multicolumn{10}{|c|}{ Functional limitations } \\
\hline $\begin{array}{l}\text { Going up } \\
\text { stairs }\end{array}$ & 79.8 & 80.3 & 69.5 & 82.6 & 92.2 & 81.3 & 70.6 & 87.4 & 78.8 \\
\hline $\begin{array}{l}\text { Walking } \\
\text { across room }\end{array}$ & 40.1 & 41.4 & 38.9 & 37.8 & 44.5 & 45.6 & 45.7 & 22.5 & 31.5 \\
\hline Bending & 52.9 & 55.9 & 40.6 & 51.4 & 62.9 & 47.4 & 24.8 & 49.7 & 51.6 \\
\hline $\begin{array}{l}\text { Lifing 10-lb } \\
\text { package }\end{array}$ & 62.0 & 62.6 & 56.8 & 62.6 & 68.3 & 47.1 & 69.8 & 77.3 & 61.3 \\
\hline $\begin{array}{l}\text { Reaching } \\
\text { above head }\end{array}$ & 35.9 & 38.7 & 31.7 & 32.0 & 32.5 & 25.2 & 19.9 & 30.0 & 37.6 \\
\hline $\begin{array}{l}\text { Grasping } \\
\text { small } \\
\text { objects }\end{array}$ & 32.7 & 34.3 & 29.9 & 29.1 & 29.8 & 33.8 & 20.2 & 14.8 & 33.7 \\
\hline $\begin{array}{l}\text { Seeing to } \\
\text { read } \\
\text { newsprint }\end{array}$ & 20.4 & 20.0 & 16.9 & 24.1 & 12.0 & 18.0 & 16.7 & 16.9 & 41.5 \\
\hline Speaking & 1.7 & 2.5 & 0.0 & 0.8 & 0.0 & 0.0 & 0.0 & 0.0 & 2.0 \\
\hline Hearing & 6.7 & 6.8 & 4.1 & 7.2 & 5.5 & 4.0 & 0.0 & 1.9 & 14.8 \\
\hline \multicolumn{10}{|l|}{ IADLs } \\
\hline $\begin{array}{l}\text { Light } \\
\text { housework }\end{array}$ & 20.5 & 22.3 & 21.8 & 14.5 & 13.1 & 10.5 & 23.7 & 9.2 & 17.2 \\
\hline Laundry & 26.3 & 28.4 & 27.9 & 21.5 & 20.3 & 18.3 & 41.2 & 16.4 & 21.9 \\
\hline Cooking & 22.5 & 24.4 & 25.6 & 17.8 & 16.9 & 20.4 & 23.2 & 11.2 & 20.0 \\
\hline $\begin{array}{l}\text { Grocery } \\
\text { shopping }\end{array}$ & 41.4 & 44.1 & 39.7 & 38.5 & 35.0 & 39.5 & 53.0 & 37.1 & 41.2 \\
\hline $\begin{array}{l}\text { Managing } \\
\text { money }\end{array}$ & 22.3 & 25.5 & 24.1 & 14.3 & 6.0 & 13.3 & 24.1 & 10.6 & 24.8 \\
\hline $\begin{array}{l}\text { Taking } \\
\text { medications }\end{array}$ & 27.2 & 28.5 & 26.6 & 24.5 & 22.3 & 22.6 & 16.4 & 12.5 & 34.0 \\
\hline $\begin{array}{l}\text { Using } \\
\text { telephone }\end{array}$ & 11.9 & 12.2 & 9.9 & 11.8 & 4.5 & 12.0 & 6.5 & 7.3 & 21.9 \\
\hline $\begin{array}{l}\text { Getting } \\
\text { around } \\
\text { outside }\end{array}$ & 71.7 & 71.1 & 70.8 & 73.5 & 82.4 & 86.2 & 79.9 & 71.1 & 66.8 \\
\hline \multicolumn{10}{|l|}{ ADLs } \\
\hline Eating & 12.2 & 13.1 & 12.8 & 10.6 & 11.2 & 5.0 & 7.3 & 1.6 & 17.3 \\
\hline $\begin{array}{l}\text { Getting out } \\
\text { of bed }\end{array}$ & 33.6 & 35.1 & 34.9 & 30.0 & 37.9 & 29.2 & 36.0 & 13.3 & 27.8 \\
\hline $\begin{array}{l}\text { Getting } \\
\text { around } \\
\text { inside }\end{array}$ & 47.0 & 48.4 & 48.2 & 44.1 & 51.3 & 44.3 & 38.3 & 59.0 & 40.1 \\
\hline Dressing & 20.3 & 23.5 & 17.6 & 15.1 & 11.5 & 12.4 & 11.4 & 11.3 & 22.6 \\
\hline Bathing & 60.0 & 64.7 & 60.0 & 52.2 & 49.5 & 42.3 & 52.2 & 57.8 & 57.2 \\
\hline Toileting & 33.9 & 35.3 & 32.3 & 31.6 & 37.0 & 30.2 & 18.4 & 19.8 & 34.6 \\
\hline
\end{tabular}




\section{References}

Aguero-Torres, H., L. Fratiglioni, et al. (1998). "Dementia is the major cause of functional dependence in the elderly: 3-year follow-up data from a populationbased study." American Journal of Public Health 88(10): 1452-1456.

Boult, C., M. Altmann, et al. (1996). "Decreasing disability in the 21st century: the future effects of controlling six fatal and nonfatal conditions." American Journal of Public Health 86(10): 1388-93.

Chernew, M. E., D. P. Goldman, et al. (2005). "Disability and health care spending among Medicare beneficiaries." Health Affairs 24(2): W5R42-W5R51.

Crimmins, E. M., Y. Saito, et al. (1997). "Further evidence on recent trends in the prevalence and incidence of disability among older Americans from two sources: the LSOA and the NHIS." J Gerontol B Psychol Sci Soc Sci 52(2): S59-71.

Cummings, J. L. and G. Cole (2002). "Alzheimer Disease." Journal of the America Medical Association 287(18): 2335-2338.

Cutler, D. M. (2001). "Declining disability among the elderly." Health Affairs 20(6): 1127.

Cutler, D. M. (2005). Intensive medical technology and the reduction in disability. Analyses in the Economics of Aging. D. A. Wise. Chicago, The University of Chicago Press: 161-184.

Dunlop, D. D., S. L. Hughes, et al. (1997). "Disability in activities of daily living: Patterns of change and a hierarchy of disability." American Journal of Public Health 87(3): 378-383.

Dunlop, D. D., L. M. Manheim, et al. (2002). "Incidence of functional limitations in older adults: The impact of gender, race, and chronic conditions." Archives of Physical Medicine and Rehabilitation 83(7): 964-971.

Ettinger, W. H., Jr., L. P. Fried, et al. (1994). "Self-reported causes of physical disability in older people: the Cardiovascular Health Study. CHS Collaborative Research Group." Journal of the American Geriatrics Society 42(10): 1035-44.

Ettinger, W. H., Jr., L. P. Fried, et al. (1994). "Self-reported causes of physical disability in older people: the Cardiovascular Health Study. CHS Collaborative Research Group." J Am Geriatr Soc 42(10): 1035-44.

Ferrucci, L., J. M. Guralnik, et al. (1998). "Constant hierarchic patterns of physical functioning across seven populations in five countries." Gerontologist 38(3): 286294.

Ferrucci, L., J. M. Guralnik, et al. (1997). "Hospital diagnosis, medicare charges, and nursing home admissions in the year when older persons become severly disabled." Journal of the American Medical Association 277(9): 728-734.

Ferrucci, L., J. M. Guralnik, et al. (1996). "Progressive versus catastrophic disability: a longitudinal view of the disablement process." Journals of Gerontology. Series A, Biological Sciences and Medical Sciences 51(3): M123-30.

Ford, A. B., S. J. Folmar, et al. (1988). "Health and function in the old and very old." Journal of the American Geriatric Society 36: 187-197.

Freedman, V. A., E. M. Crimmons, et al. (2004). "Resolving inconsistencies in trends in old-age disability: report from a technical working group." Demography 41(3): 417-441. 
Freedman, V. A. and L. G. Martin (1998). "Understanding trends in functional limitations among older Americans." American Journal of Public Health 88(10): 1457-1462.

Freedman, V. A., L. G. Martin, et al. (2002). "Recent trends in disability and functioning among older adults in the United States: A systematic review." Journal of the American Medical Association 288(24): 3137-3146.

Fried, L. P., K. Bandeen-Roche, et al. (2000). "Preclinical mobility disability predicts incident mobility disability in older women." J Gerontol Med Sci 55: M43-52.

Fried, L. P., K. Bandeen-Roche, et al. (1996). "Functional decline in older adults: expanding methods of ascertainment." J Gerontol A Biol Sci Med Sci 51(5): M206-M214.

Fried, L. P., W. H. Ettinger, et al. (1994). "Physical disability in older adults: A physiological approach." Journal of Clinical Epidemiology 47(7): 747-760.

Fried, L. P., L. Ferrucci, et al. (2004). "Untangling the concepts of disability, frailty, and comorbidity: Implications for improved targeting and care." Journals of Gerontology. Series A, Biological Sciences and Medical Sciences 59(3): M255263.

Fried, L. P., S. J. Herdman, et al. (1991). "Preclinical disability: hypotheses about the bottom of the iceberg." J Aging Health 3: 285-300.

Fried, L. P., Y. Young, et al. (2001). "Self-reported preclinical disability identifies older women with early declines in performance and early disease." J Clin Epidemiol 54: 889-901.

Fried, T. R., E. H. Bradley, et al. (2001). "Functional disability and health care expenditures for older persons." Archives of Internal Medicine 161: 2602-2607.

Gill, T. M., H. G. Allore, et al. (2006). "The dynamic nature of mobility disability in older persons." Journal of the American Geriatrics Society 54(2): 248-254.

Gill, T. M., E. A. Gahbauer, et al. (2006). "Transitions between frailty states among community-living older persons." Arch Intern Med 166(4): 418-23.

Gill, T. M., J. T. Robinson, et al. (1998). "Difficulty and dependence: Two components of the disability continuum among community-living older persons." Annals of Internal Medicine 128(2): 96-101.

Gill, T. M., J. T. Robison, et al. (1997). "Predictors of recovery in activities of daily living among disabled older persons living in the community." J Gen Intern Med 12(12): 757-762.

Greenland, S. and K. Drescher (1993). "Maximum likelihood estimation of the attributable fraction from logistic models." Biometrics 49(3): 865-72.

Guccione, A. A., D. T. Felson, et al. (1994). "The effects of specific medical conditions on the functional limitations of elders in the Framingham Study." American Journal of Public Health 84(3): 351-8.

Guralnik, J. M., L. Alecxih, et al. (2002). "Medical and long-term care costs when older persons become more dependent." American Journal of Public Health 92(8): 1244-1245.

Guralnik, J. M., L. Ferrucci, et al. (1995). "Lower-extremity function in persons over the age of 70 years as a predictor of subsequent disability." N Engl J Med 332: 556561.

Guralnik, J. M., A. Z. LaCroix, et al. (1991). "Morbidity and disability in older persons in the years prior to death." American Journal of Public Health 81: 443-447. 
Iezzoni, L. I., S. M. Foley, et al. (1992). "Comorbidities, complications and coding bias: Does the number of diagnosis codes matter in predicting in-hospital mortality?" Journal of the American Medical Association 267(16): 2197-2203.

Jagger, C., A. J. Arthur, et al. (2001). "Patterns of onset of disability in activities of daily living with age." J Am Geriatr Soc 49: 404-409.

Jencks, S. F., D. K. Williams, et al. (1988). "Assessing hospital-associated deaths from discharge data: the role of length of stay and comorbidities." Journal of the American Medical Association 260: 2240-2246.

Katz, S., A. B. Ford, et al. (1963). "Studies of illness in the aged. The index of ADL: A standardized measure of biological and psychosocial function." Journal of the America Medical Association 185(914-919).

Kempen, G. I. and T. P. Suurmeijer (1990). "The development of a hierarchical polychotomous ADL-IADL scale for noninstitutionalized elders." Gerontologist 30(4): 497-502.

Komisar, H. L., J. Hunt-McCool, et al. (1997). "Medicare spending for elderly beneficiaries who need long-term care." Inquiry 34(4): 302-10.

Kosorok, M. R., G. S. Omenn, et al. (1992). "Restricted activity days among older adults." American Journal of Public Health 82: 1263-1267.

Lakdawalla, D. N., J. Bhattacharya, et al. (2004). "Are the young becoming more disabled?" Health Affairs 23(1): 168-176.

Lamb, V. L. (1996). "A cross-national study of quality of life factors associated with patterns of elderly disablement." Social Science and Medicine 42(3): 363-77.

Lazaridis, E. N., M. A. Rudberg, et al. (1994). "Do activities of daily living have a hierarchical structure? An analysis using the longitudinal study of aging." Journal of Gerontology 49(2): M47-M51.

Leveille, S. G., L. P. Fried, et al. (2002). "Disabling symptoms: What do older women report?" Journal of General Internal Medicine 17: 766-773.

Leveille, S. G., L. P. Fried, et al. (2004). "Advancing the taxonomy of disability in older adults." Journals of Gerontology. Series A, Biological Sciences and Medical Sciences 59A(1): 86-93.

Leveille, S. G., L. P. Fried, et al. (2004). "Advancing the taxonomy of disability in older adults." J Gerontol A Biol Sci Med Sci 59A(1): 86-93.

Leveille, S. G., C. C. Wee, et al. (2005). "Trends in obesity and arthritis among baby boomers and their predecessors, 1971-2002." American Journal of Public Health 95(9): 1607.

Liu, K., S. Wall, et al. (1997). "Disability and Medicare costs of elderly persons." Milbank Q 75(4): 461-493.

Lunney, J. R., J. Lynn, et al. (2003). "Patterns of functional decline at the end of life." Journal of the American Medical Association 289(18): 2387-2392.

Manton, K. G. (1988). "A longitudinal study of functional change and mortality in the United States." Journal of Gerontology 43(5): S153-S161.

Manton, K. G. (1989). "Epidemiological, demographic, and social correlates of disability among the elderly." Milbank Quarterly 67 Suppl 2 Pt 1: 13-58.

Manton, K. G. and X. Gu (2001). "Changes in the prevalence of chronic disability in the United States black and nonblack population above age 65 from 1982 to 1999." 
Proceedings of the National Academy of Sciences of the United States of America 98(11): 6354-6359.

Manton, K. G., X. Gu, et al. (2006). "Change in chronic disability from 1982 to 2004/2005 as measured by long-term changes in function and health in the U.S. elderly population." Proceedings of the National Academy of Sciences of the United States of America 103(48): 18374-9.

Manton, K. G., E. Stallard, et al. (1998). "The dynamics of dimensions of age-related disability 1982 to 1994 in the U.S. elderly population." J Gerontol A Biol Sci Med Sci 53(1): B59-70.

McClellan, M. and L. Yan (2000). Understanding disability trends in the U.S. elderly population: The role of disease management and disease prevention. Department of Economics. Stanford University.

Schoeni, R. F., V. A. Freedman, et al. (2001). "Persistent, consistent, widespread, and robust? Another look at recent trends in old-age disability." Journal of Gerontology 56B(4): S206-S218.

Singer, B. H. and K. G. Manton (1998). "The effects of health changes on projections of health service needs for the elderly population of the United States." Proceedings of the National Academy of Sciences of the United States of America 95(26): 15618-22.

Siu, A. L., R. D.B., et al. (1990). "Hierarchical measures of physical functioning in ambulatory geriatrics." Journal of the American Geriatrics Society 38(10): 11131119.

Song J, Chang RW, et al. (2006). "Population impact of arthritis on disability in older adults." Arthritis and Rheumatism 55(2): 248-255.

Spector, W. D. and J. A. Fleishman (1998). "Combining activities of daily living with instrumental activities of daily living to measure functional disabiltiy." Journal of Gerontology 53B(1): S46-S57.

Spillman, B. C. (2004). "Changes in elderly disability rates and the implications for health care utilization and cost." Milbank Quarterly 82(1): 157-194.

Valderrama-Gama, E., J. Damian, et al. (2002). "Chronic disease, functional status, and self-ascribed causes of disability among noninstitutionalized older people in Spain." Journal of Gerontology 57A(11): M716-M721.

Verbrugge, L. M., J. M. Lepkowski, et al. (1991). "Levels of disability among U.S. adults with arthritis." Journal of Gerontology 46(2): S71-S83.

Verbrugge, M. and A. M. Jette (1994). "The disablement process." Soc Sci Med 38(1): 114.

Waidmann, T. A. and K. Liu (2000). "Disability trends among elderly persons and implications for the future." Journal of Gerontology 55B(5): S298-S307.

Williamson, J. D. and L. P. Fried (1996). "Characterization of older adults who attribute functional decrements to "Old Age"." Journal of the American Geriatrics Society 44(12).

Williamson, J. D. and L. P. Fried (1996). "Characterization of older adults who attribute functional decrements to "Old Age"." J Am Geriatr Soc 44(12).

Wolff, J. L., C. Boult, et al. (2005). "Newly reported chornic conditions and onset of functional dependency." Journal of the American Geriatrics Society 53(5): 851855. 